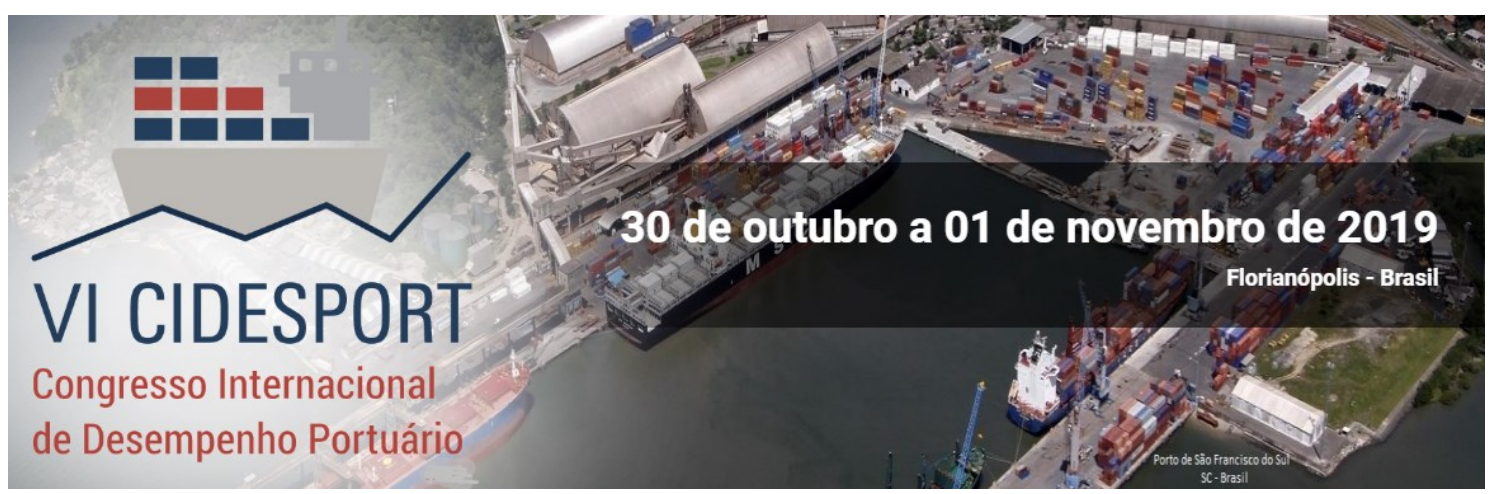

\title{
METODOLOGIA ALTERNATIVA PARA AUMENTO POTENCIAL DA CAPACIDADE OPERACIONAL DE NAVIOS NOS PORTOS BRASILEIROS A PARTIR DA UTILIZAÇÃO DE REBOCADORES PORTUÁRIOS
}

\section{Universidade Federal do Rio de Soares \\ Leonardo S. Soares
ral do Rio de Janeiro}

Resumo: O presente artigo possui finalidade de apresentar uma metodologia alternativa e inovadora de utilização de rebocadores portuários em assistência na manobra de navios, com a finalidade precípua de reduzir a velocidade de trânsito de navios no canal de acesso aos portos e terminais. Esta redução de velocidade apresenta, por consequência, um efeito de redução no afundamento da embarcação pela ação de ondas e devido ao efeito Squat, aumentando-se o parâmetro de navegação denominado folga abaixo da quilha. Finalmente, o propósito final do trabalho é converter este incremento deste parâmetro em aumento de calado, proporcionando ao armador do navio um aumento de carga a ser transportada e, em alguns casos, aumento de receita, dependendo do valor de frete pactuado (dentro de um contrato de afretamento) entre armador e afretador, e valores de afretamento dos rebocadores. O método proposto poderá ser utilizado como instrumento de apoio à tomada de decisão por diretores e gestores da área comercial de uma empresa de navegação ou, uma empresa administradora de um porto ou terminal, que pretendam eliminar limitações portuárias utilizando-se de rebocadores portuários.

Palavras-chave: Folga abaixo da quilha. Utilização de rebocadores nos portos. Aumento da capacidade de navios.

Abstract: This article aims to present an innovating and alternative methodology of use of harbour tugs in assisting the ships' maneuvers in ports, with the primary purpose of reducing the ship's transit speed in the access channels to ports and terminals. This reduction of ship's speed has the consequence of minimizing ship's sinkage due to waves and squat effect as well. Moreover, such reduction in the ship's sinkage is converted in an increase of the navigation parameter know as underkeel clearance value. Finally, the final purpose of the article is convert this increase of underkeel clearance in increase of ship's draft, providing the ship's owner an increase of cargo to be shipped and, in some cases, an increase of incomes, according to charter rates settled within a contract of affreightment, and tug's charter prices. The proposed methodology can be used as a tool (in the decision-making process) by commercial directors or managers of ship's companies, as well as port's companies, which intends to remove port's restrictions, by using harbour tugs in assisting ship's maneuvers.

Keywords: Underkeel clearance. Tug use in port. Increase in ship's capacity.

* A revisão gramatical, ortográfica, ABNT ou APA foi realizada pelos autores. 


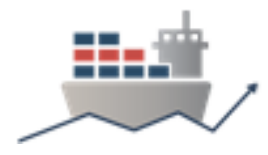

\section{INTRODUÇÃO E MOTIVAÇÃO}

Nos últimos anos, engenheiros e arquitetos navais apresentaram ao mundo os maiores e mais potentes navios já construídos. Embarcações de granel sólido de 400.000 TPB com seus 23 metros de calado, os chamados "CHINAMAX" tornaramse uma realidade em portos nacionais, europeus e asiáticos. No que tange $O$ transporte de carga em contêineres, os navios "Post-Panamax" e "New-Panamax", com respectivamente 8500 TEU s e 12500 TEUs também se tornaram uma realidade nos principais "hub" portos mundiais.

Adicionalmente ao aumento das principais dimensões (comprimento total, boca e calado), os navios passaram a ter maior potência nas suas máquinas, apresentando velocidades mínimas de operação superiores aos valores máximos admissíveis para manutenção da segurança da navegação em muitos portos mundiais. E este aumento de velocidade inicial é um fator indesejável à navegação e manobra do navio em áreas portuárias, pois exige maior habilidade de controle do seu curso e aproamento por parte dos agentes envolvidos na manobra, quais sejam estes: comandante do navio, prático, rebocadores, entre outros. Além disso, uma alta velocidade inicial gera um maior afundamento do navio em ondas e afundamento maior devido ao efeito Squat.

Trazendo para o caso nacional o fato dos navios mais modernos possuírem uma maior velocidade inicial, verifica-se que a grande parte dos portos brasileiros permaneceu, ao longo dos anos, enclausurada pelas cidades no seu entorno, e, em vista disso, não sofreu significativas mudanças de traçado, largura, profundidade. Com isso, percebe-se que muitos dos nossos portos não estão adequados para receber a próxima geração de grandes navios. Em vista disso, é necessário o emprego de novas técnicas nas manobras de navios, com o objetivo de fazer com que os portos brasileiros estejam preparados para receber esta próxima frota de grandes e mais potentes embarcações. Ademais, ao tornar viável a manobra destas embarcações em portos nacionais, contribui-se para a redução dos custos do transporte internacional pelo emprego de maiores navios (maior economia de escala), eliminando-se também alguns gargalos logísticos que ainda permanecem como um dos maiores entraves ao desenvolvimento nacional.

Novas técnicas de utilização de rebocadores já são usadas em alguns portos europeus (ex: Rotterdam - Holanda) e asiáticos (ex: Cingapura), com o desiderato específico de redução dos valores de velocidade de trânsito dos navios nos canais de acesso (sobretudo aqueles que estejam procedendo para atracação e precisam estar com velocidades próximas de zero na bacia de evolução). Por exemplo, a utilização de rebocadores no método indireto de reboque (para gerar forças de frenagem ao navio), método este que, ainda não é amplamente utilizado no Brasil, pode ser uma destas alternativas.

Em contrapartida aos métodos usuais de utilização de rebocadores nas manobras, este artigo apresenta uma metodologia alternativa de uso desta ferramenta de auxílio de manobra de navios e, também, de mitigação das restrições existentes nas áreas portuárias. A metodologia proposta possui finalidade precípua de utilizar rebocadores para se reduzir a velocidade de trânsito dos navios nos canais de acesso, reduzindo também os valores de afundamento devido a ondas e efeito Squat.

Diante dessa hipótese, utilizou-se um simulador de manobras de navios para analisar um exemplo quantitativo do aumento de folga abaixo da quilha a partir da redução de velocidade de trânsito dos navios, sob a égide da metodologia alternativa de uso de rebocadores. Para haver consonância com as manobras no caso real, 


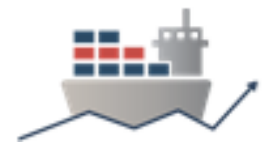

escolheu-se um porto cujo canal de acesso possui restrições de velocidade de trânsito dos navios, em conjunto com parâmetros de condições ambientais que limitam algumas manobras no porto escolhido.

Os resultados de aumento de folga abaixo da quilha foram significativos, em algumas das condições ambientais analisadas, o que levou uma solução alternativa aos métodos comumente empregados para se manter uma adequada folga abaixo da quilha: reduzir o calado do navio ou optar por dragagem dos canais de acesso.

Ademais, a partir dos dados e do aumento nos valores de folga abaixo da quilha, obteve-se uma solução alternativa para aumentar-se a capacidade dos navios, transformando o aumento de calado multiplicado pelo valor do TPC (toneladas por centímetro de imersão) do navio em quantidade de carga a ser embarcada.

Finalmente, ao fazer uma análise de custo-benefício (trade-off) entre o aumento de receita (dado pelo aumento da capacidade de carga), de acordo com valores diferentes de frete (U\$D / ton), pelo aumento de custo em virtude do aumento do número de rebocadores, de acordo com a proposta de emprego de uso de rebocadores, obteve-se algumas situações que o aumento potencial de receita foi bastante significativo, o que compensaria em demasia o emprego desta metodologia no propósito de se maximizar receitas para vários agentes (armador, autoridade portuária, dono da carga, etc).

\section{REVISÃO BIBLIOGRÁFICA}

Durante a realização desta pesquisa, foi constatada uma escassez de referências bibliográficas existentes sobre rebocadores portuários, sobretudo aquelas relacionadas com o uso de rebocadores para gerar forças adicionais de frenagem nos navios. No Brasil, foi publicado em 2017 pela Autoridade Marítima Brasileira (Marinha do Brasil) a primeira versão do livro "Utilização de Rebocadores nos Portos", que passou a nortear as operações e projetos de novas construções de rebocadores, aumentando o nível de conhecimento sobre manobras com rebocadores nos portos brasileiros. Este livro, tradução da publicação "Tug Use in Ports" (IMO MSC 1.101), teve chancela da Diretoria Geral de Navegação e Diretoria de Portos e Costas, como representante da Autoridade Marítima para segurança da navegação, de forma que a obra disponibiliza conhecimento técnico de assunto tão pouco explorado no Brasil, em que pese tenha relevante importância para as operações portuárias do cotidiano.

A principal referência bibliográfica sobre o assunto é o livro "Tug Use in Ports" [1], de autoria do comandante e prático holandês Henk Hensen. Por sua vez, sobre o tema planejamento portuário e aspectos náuticos, as principais referencias nacionais e internacionais são a norma ABNT NBR 13246 [2] e o Relatório Técnico 121/2014 da PIANC [3], respectivamente. Entretanto, quando se trata de ter uma referência que lide com uso de rebocadores para controle e redução da velocidade do navio, o artigo que mais se contribuiu neste tópico foi publicado por TEJADA [4], na Conferência MARSIM, no Panamá, em 2009.

Diante do exposto em epígrafe é notável a escassez de trabalhos acadêmicos que lidam com o uso de rebocadores portuários para reduzir a velocidade de navios, adequando esta realidade aos portos nacionais e, por óbvio, preservando a segurança da navegação. Dessa forma, este artigo traz uma metodologia inovadora, ilustrada na figura 1 abaixo, que trata da utilização de rebocadores para redução da velocidade dos grandes navios nos portos brasileiros, viabilizando seu trânsito nos referidos canais de acesso. 


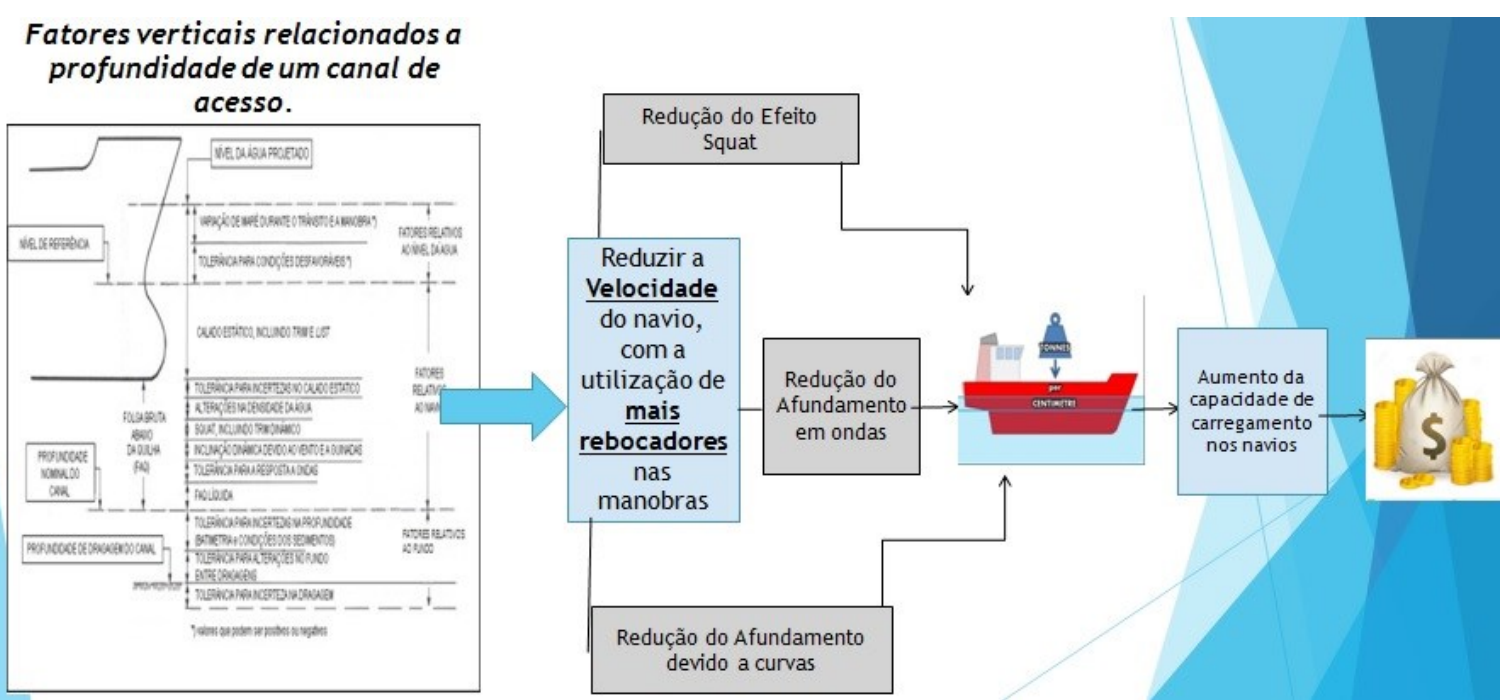

Figura 1: Fluxograma representando a proposta de ganho potencial de capacidade.

\section{DEFINIÇÃO DO PROBLEMA}

No projeto de construção ou ampliação de um canal de acesso, ocasião que ocorre, por exemplo, para se permitir um aumento de capacidade do porto, faz-se necessário o conhecimento de fatores que influenciam as manobras dos navios e a segurança da navegação em áreas restritas.

Estes fatores, de acordo com PIANC [3], são divididos em:

- $\quad$ Fatores relativos a dimensões verticais do canal de acesso;

- $\quad$ Fatores relativos a dimensões horizontais do canal de acesso.

Os fatores relativos às dimensões horizontais são referenciados ao comprimento e boca do maior navio-tipo a ser manobrado no canal de acesso e área portuária, em conjunto com fatores ambientais e externos, quais sejam: vento, ondas, correntes, auxílios a navegação, superfície e tipo de fundo, etc. Estes parâmetros não influenciam a folga abaixo da quilha (calculada pela subtração da profundidade menos o calado do navio) e não estarão em análise neste trabalho.

Entretanto, os fatores relativos as dimensões verticais influenciam a folga abaixo da quilha, pois alteram o nível da profundidade de água no local ou, alteram o valor do calado estático do navio. Estes fatores, de acordo com PIANC [3], ilustrados na figura 2 a seguir, são subdivididos em:

i. Fatores relativos ao nível da água:

$>\quad$ Variação de maré durante o trânsito e manobra;

> Tolerância para condições desfavoráveis

ii. Fatores relativos ao navio:

> Calado estático, incluindo trim e banda;

> Tolerância para incertezas do calado estático;

$>\quad$ Efeito squat, incluindo trim dinâmico;

> Inclinação dinâmica devido a vento e guinadas;

> Tolerância para resposta a ondas;

> Folga abaixo da quilha líquida

iii. Fatores relativos ao fundo:

> Tolerância para incertezas na profundidade;

> Tolerância para alterações no fundo entre dragagens;

> Tolerância para incerteza na dragagem. 

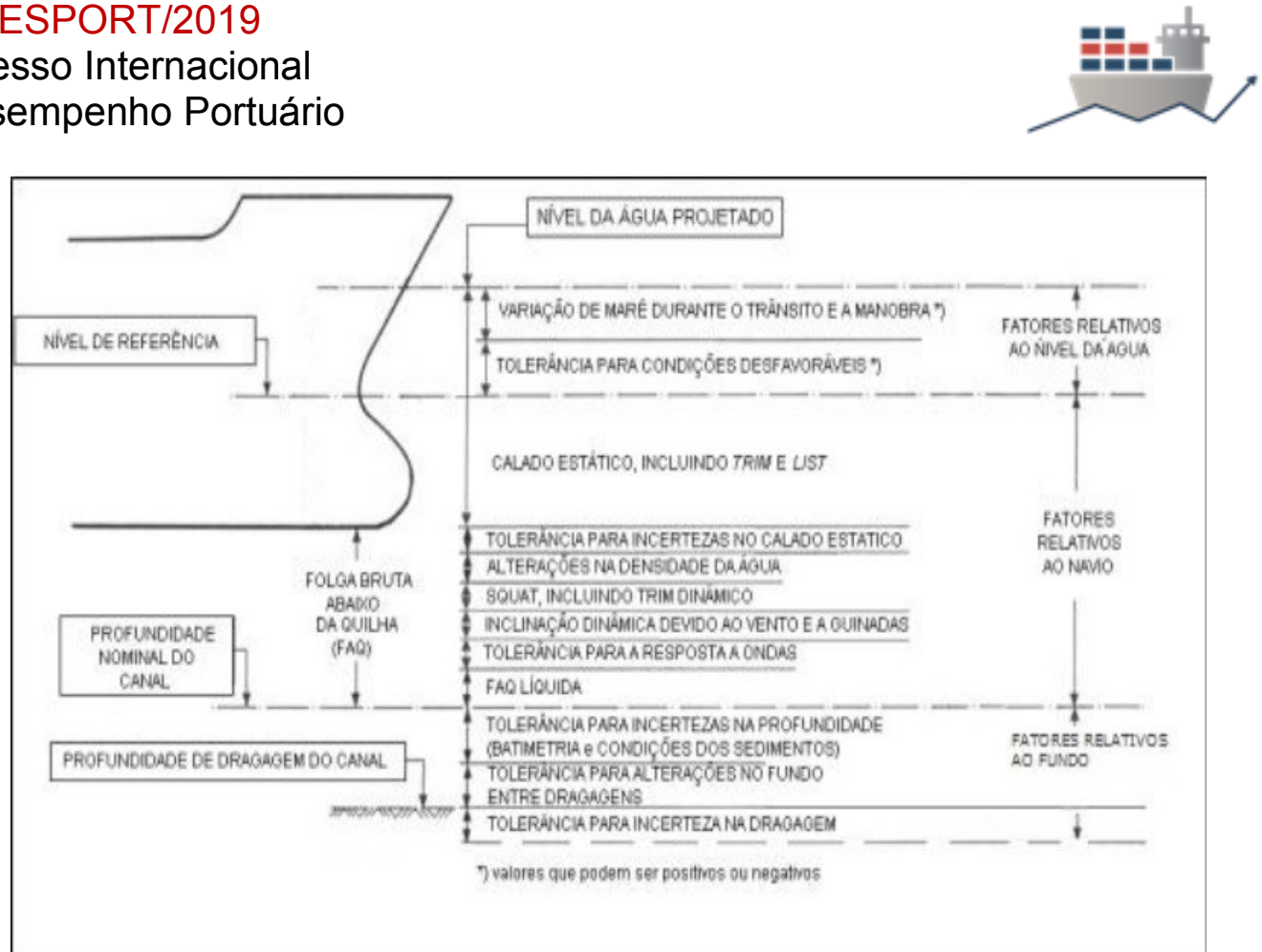

Figura 2: Fatores verticais relacionados a profundidade de um canal de acesso. Tradução de PIANC [3].

Os fatores relacionados ao nível da água - citados em "i” - baseiam-se no nível da altura da maré no momento da manobra do navio no canal de acesso. Por óbvio, estes fatores não podem controlados pelos operadores do navio (prático, comandante, tripulação, etc), apenas adequados ao instante da manobra para deixar o valor mínimo de folga abaixo da quilha para o navio navegar e não encalhar.

Os fatores relacionados ao fundo - citados em "iii" - também são concernentes ao canal de acesso ao porto que o navio está navegando, e se relacionam também ao processo de transporte de sedimentos que ocorre no canal de acesso, que pode diminuir o valor de profundidade dragada no canal, e consequentemente, o valor da folga abaixo da quilha líquida. Em portos onde há lama de baixa densidade, pode ocorrer a interação entre a lama e o fundo náutico, reduzindo ainda mais o valor da folga abaixo da quilha, conforme apresentaram CASACA, et al. [5].

Destarte, serão explicados em maior detalhe os 3 (três) parâmetros de maior influência na obtenção da folga abaixo da quilha "líquida", sendo estes, relacionados ao navio (citados em "ii") : efeito Squat; efeito do afundamento do navio ao fazer curvas (inclinação dinâmica) e, efeito do afundamento do navio em ondas.

\section{Efeito Squat}

Quando embarcações, independente do porte, classe ou tipo, estão navegando próximas a umas das outras, é perceptível que cada uma delas perceba a presença das demais, seja de uma forma maior ou menor, conforme expôs BARRASS [6]. A este efeito, denominado interação, resultado da diferença de campos de pressão no fluido, pode manifestar-se de várias formas, desde a indução indesejável de velocidades, mudanças no aproamento ou, reduções na distância entre a quilha da embarcação e o fundo. O último efeito citado em epígrafe resulta do fenômeno bem conhecido na engenharia naval denominado efeito Squat. 


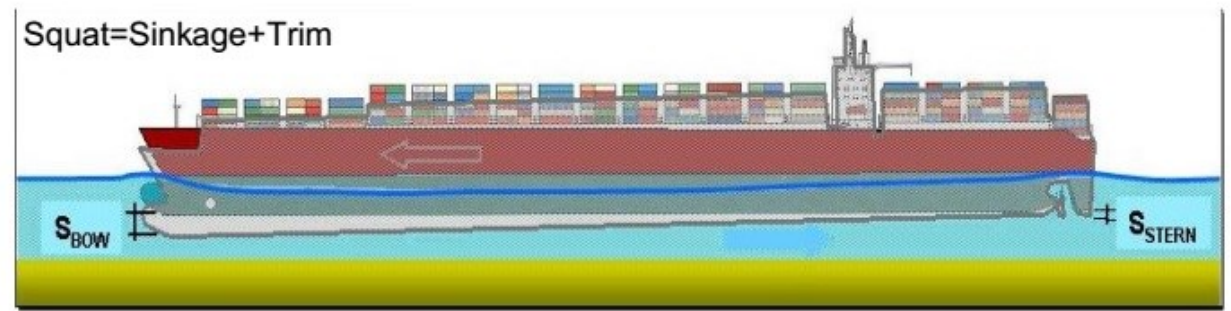

Figura 3: llustração do efeito Squat em um navio navegando em velocidade. Fonte: PIANC [3].

A previsibilidade do efeito Squat depende das características do navio e configuração do canal de acesso. Os principais parâmetros concernentes ao navio são: o calado, representado pela letra "T"; o coeficiente de bloco, $\mathrm{CB}_{\mathrm{B}}{ }^{1}$; e a velocidade do navio, representado por Vs. Cabe lembrar que esta é a velocidade do navio na água, logo, de acordo com PIANC [3], devem-se incluir os efeitos causados pelas correntes de rios próximos ao canal de acesso e, correntes de marés.

$O$ coeficiente de bloco $C_{B}$ é uma medida adimensional de um navio, que reflete o quanto de volume do casco dele está sendo ocupado por um paralelepípedo retoretângulo circunscrito a este navio.

Um artigo recente de cálculos de afundamento e influência direta do coeficiente de bloco foi o de GRONARZ [7], cujos resultados de algumas fórmulas de Squat e sua dependência com o parâmetro $C_{B}$ são expostas na figura abaixo:

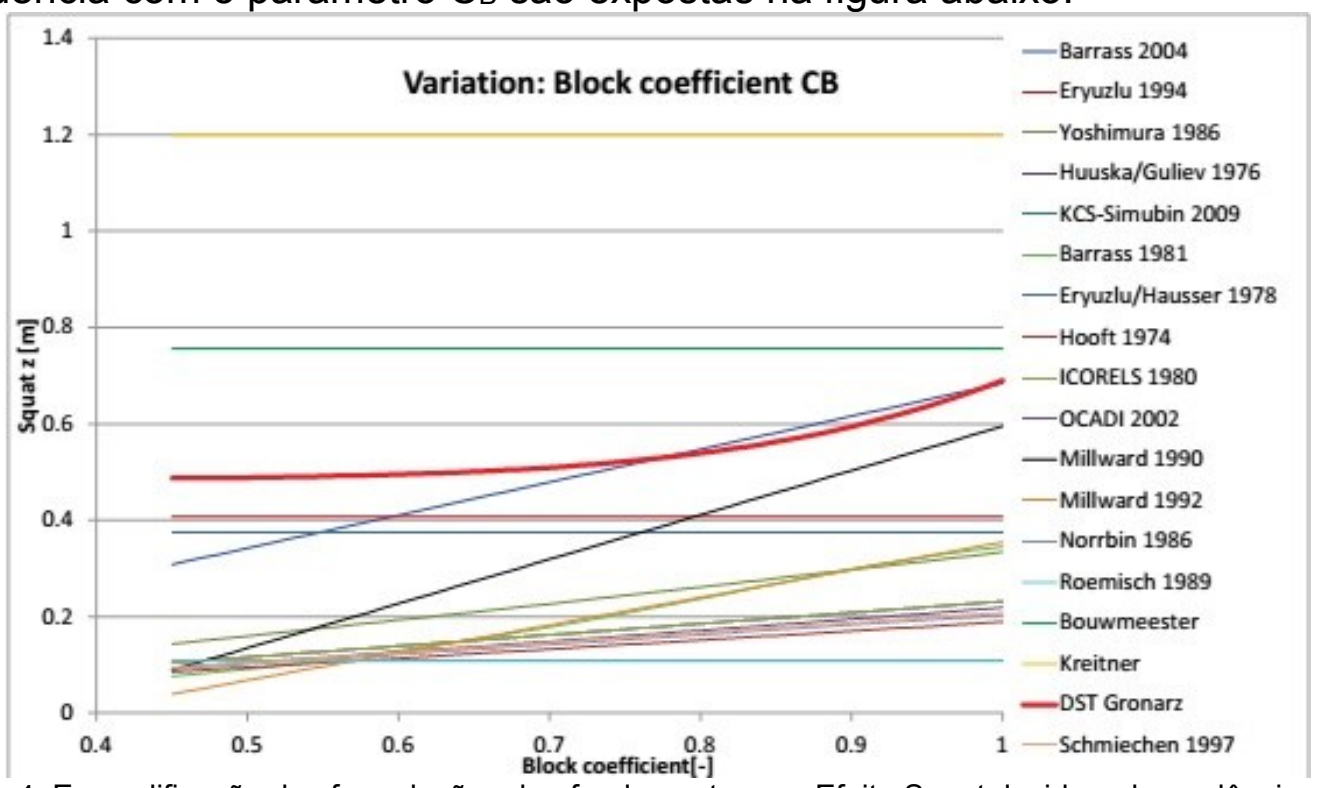

Figura 4: Exemplificação das formulações do afundamento para Efeito Squat devido a dependência do $C_{B}$. Fonte: GRONARZ [7].

De todas as fórmulas citadas e explicadas no relatório do PIANC [3], apenas para clareza da explicação, cita-se a fórmula simplificada de Romisch² (1989). Esta é

\footnotetext{
1 O Coeficiente de bloco $\left(C_{B}\right)$ é uma medida adimensional de um navio, que reflete o quanto do volume do casco dele está sendo ocupado por um paralelepípedo reto-retângulo circunscrito a este navio. É expresso pela fórmula $C_{B}=V / L_{p p} \times B \times T$, onde $V$ é o volume de carena; $L_{p p}$ é o comprimento entre perpendiculares; B é a medida da boca do navio e T é o valor do calado.

${ }^{2} \mathrm{~S}_{\mathrm{b}, \mathrm{R}}=\mathrm{C}_{V} \cdot \mathrm{C}_{\mathrm{F}} \cdot \mathrm{K}_{\Delta \mathrm{T}} . \mathrm{T}-\mathrm{Squat}$ pela proa do navio; $\mathrm{S}_{\mathrm{S}, \mathrm{R}}=\mathrm{C}_{V} . \mathrm{K}_{\Delta \mathrm{T}}$. T - Squat pela popa do navio; onde: $C_{V}=$ Fator de correção para a velocidade do navio; Calculado por : $C_{V}=8\left(\mathrm{~V} / \mathrm{V}_{\text {critica }}\right)^{2}$. [(V/ $\left.\mathrm{V}_{\mathrm{cr}}-0,5\right) 4$ $+0,0625]$
} 
a fórmula utilizada pela ferramenta de análise (simulador de manobras em modelo matemático) deste estudo, cujos resultados da análise estarão nas seções a seguir.

\section{Efeito de Afundamento em ondas}

Adicionalmente ao efeito Squat, quando o navio está navegando em um canal de acesso exposto ao efeito de ondas ou swell ${ }^{3}$, o navio sofre amplificação dos movimentos de caturro (em inglês "pitch") e arfagem (em inglês, "heave"), para ondas de proa, e balanço (em inglês "roll"), para ondas de través.Estes movimentos ocasionam um aumento de calado, e consequente diminuição na folga abaixo da quilha, na maior parte dos casos.

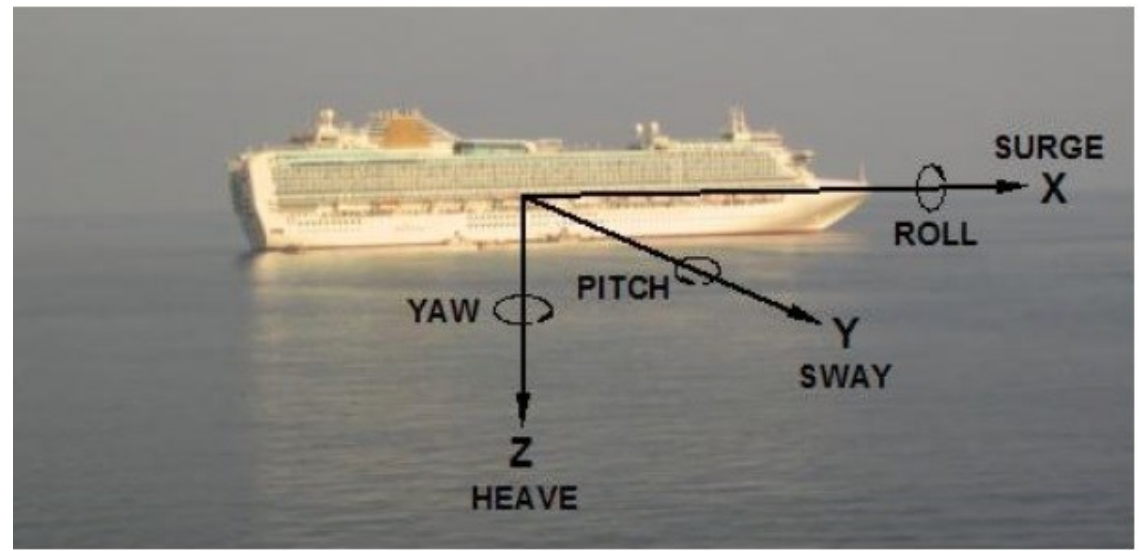

Figura 5: Apresentação dos 6 graus de liberdade de uma embarcação. Fonte : PIANC [3].

A título de exemplificação, McCARTNEY, et al. [8] reportaram um ângulo de caturro de $2,5^{\circ}$ (dois e meio graus) pode causar ao navio de 1000 pés (aproximadamente 305 metros) um afundamento de 22 pés (aproximadamente 6,7 metros) em mar aberto; já em áreas portuárias, como foram feitas observações no Rio Columbia (estado de Washington, costa oeste dos Estados Unidos) de afundamentos na ordem de 25 pés (aproximadamente 7,6 metros).

Outro aspecto importante a se considerar é o período da onda incidente. $\mathrm{O}$ período da onda corresponde a distância temporal para formação de duas cristas consecutivas. Logo, quanto maior o período, mais tempo levar-se-á para formar a próxima crista, e mais massa de água terá a próxima onda. A partir disso, deduz-se que quanto maior o período da onda incidente, maiores serão seus efeitos no afundamento do navio.

Essencial é a ressalva feita em ROM [9], que, se o navio está em movimento, o período de onda considerado é aquele conhecido como "período de encontro" ou "período aparente", o qual é o intervalo de tempo para passagem de duas cristas consecutivas por um mesmo ponto da embarcação. Consequentemente, este período de encontro não dependerá somente do período da onda incidente, mas também da velocidade da embarcação e do ângulo de incidência da onda com o aproamento da embarcação. Esta consideração permite que a embarcação, quando possível,

$\mathrm{C}_{\mathrm{F}}=$ Fator de correção para o formato do navio;Calculado por : $\mathrm{C}_{\mathrm{F}}=\left(10 \mathrm{C}_{\mathrm{B}} / \mathrm{Lpp} / \mathrm{B}\right)^{2}$

$\mathrm{K} \Delta \mathrm{T}=$ Fator de correção para Squat na velocidade crítica; Calculado por: $\mathrm{K} \Delta \mathrm{T}=0,155 . \sqrt{\mathrm{h}} / \mathrm{T}$

${ }^{3}$ Swell: ondulações geradas por vento, que não foram geradas por vento local. O swell tem cristas mais bem definidas e planas do que as ondas formadas pelo vento. O período do swell é muito regular, variando de 8 a 30 segundos, embora seja raro ocorrer períodos de 15 a 30 segundos. Fonte: ABNT [1]. 
modifique seu aproamento ou velocidade, com o objetivo de modificar as condições da sua resposta em ondas.

Apenas para exemplificação do efeito das ondas no afundamento de um navio em movimento, é apresentado na figura o estudo de GOURLAY [10], que obteve medidas de afundamento em ondas, para um navio graneleiro de 230 metros de comprimento entre perpendiculares, a partir da modelagem de ondas incidentes pela proa, com 1 (um) metro de altura e, diferentes períodos de incidência.

Ele verificou que os deslocamentos verticais significantes para este navio-tipo ocorreram a amplitude média dos $1 / 3$ (um terço) maiores movimentos em um mar irregular para os valores dados de período.

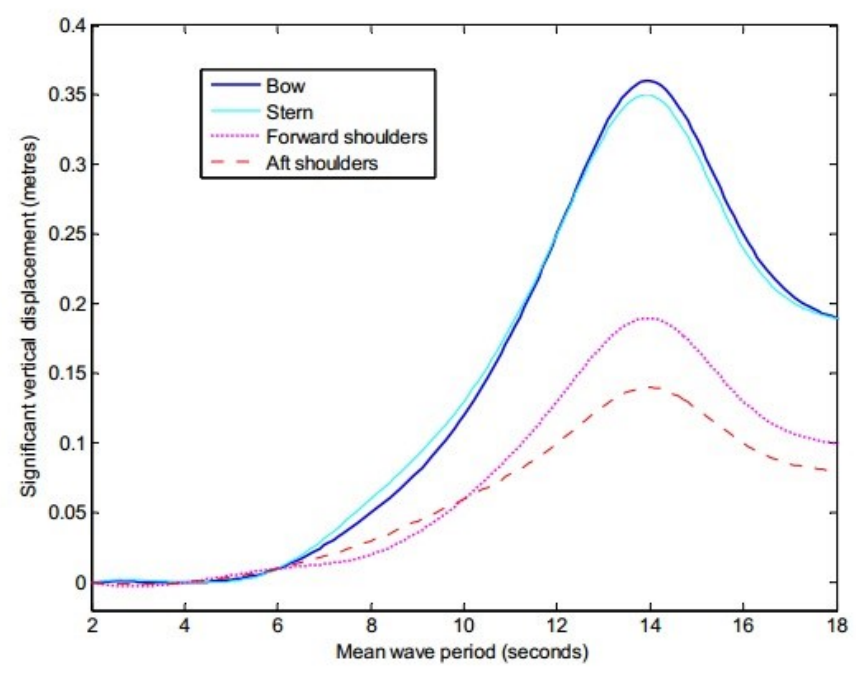

Figura 6: Exemplos de afundamento devido a ondas de proa de diferentes períodos de incidência. Fonte: GOURLAY [10].

\section{Inclinação dinâmica : afundamento devido a curvas}

O terceiro importante fator que afeta diretamente a folga abaixo da quilha de um navio navegando em um canal de acesso é a inclinação que um navio adquire ao fazer curvas em um canal, bem conhecida como inclinação dinâmica, ou em inglês, "dynamic heel".

Segundo PARKER [11], quando um navio está fazendo uma curva, atua no seu casco uma força dirigida para fora da curva, que modifica a posição do centro de carena do navio, deixando-o fora da linha de centro. Esta descentralização do centro de carena faz com que o navio adquira uma banda, de acordo com a direção da curva. A magnitude desta banda depende da velocidade do navio, do raio do giro e da altura metacêntrica do navio. Navios tipo porta-conteineres e petroleiros experimentam valores maiores de acréscimo de calado devido a esta inclinação. Complementa LEWIS [12] que esta banda ocorre devido ao fato de que, ao carregar o leme e alterar o grau de liberdade "yaw", são induzidos movimentos nos planos dos graus de liberdade "pitch" e "roll", sendo estes últimos de grande significância para a ocorrência da inclinação.

\section{METODOLOGIA E APLICAÇÃO DA MODELAGEM}

A metologia aplicada utilizou-se de um simulador de manobras de navio para analisar o aumento potencial de folga abaixo da quilha que um navio poderia obter a 
partir da redução da sua velocidade (e por consequencia, redução dos efeitos tratados no subitem " 3 " anterior).

Diante disso, a escolha do cenário para o estudo de caso levou em consideração alguns aspectos:

i. Um porto cuja normas da Autoridade Marítima impõem um valor de velocidade de trânsito maior do que o valor mínimo de velocidade das embarcações mais modernas;

ii. Um porto em que o valor de folga abaixo da quilha das manobras atuais possa ser reduzido através da redução da velocidade do navio;

iii. Um porto de exportação de carga, em que a grande parte das manobras de atracação ocorra com navios em lastro, e as desatracações ocorram com navio carregado;

iv. Um porto que receba sempre a mesma classe de navios em uma quantidade razoável, durante todos os meses.

Para cumprir com os objetivos acima, foi escolhido o cenário do porto do Rio de Janeiro, região do cais comercial, cujos canais de acesso e terminais são mostrados em detalhe na figura 7 abaixo.

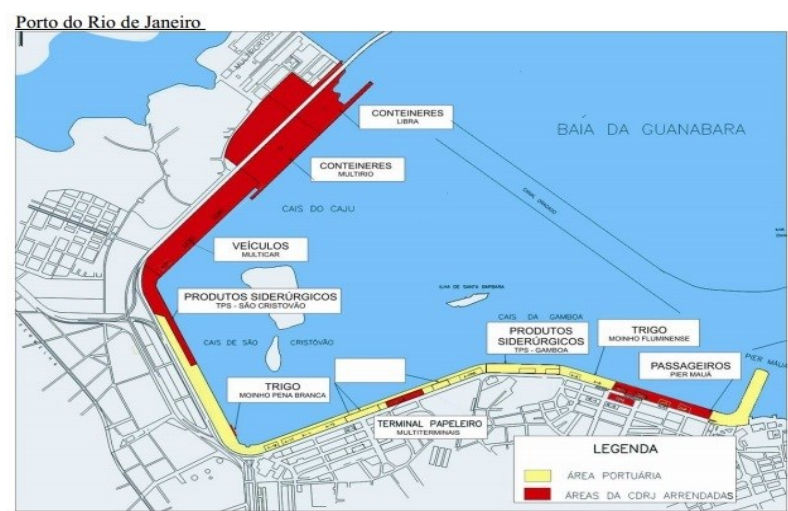

Figura 7: Vista aérea do Porto do Rio de Janeiro, com a divisão dos terminais e dos canais de acesso ao terminal de contêineres e ao porto comercial. Fonte: MARINHA DO BRASIL [13]. no modelo:

A análise levou em consideração a seguinte geografia e parâmetros inseridos

I. O canal de acesso possui aproximadamente quatro milhas de extensão entre as bóias 1 e 7 - em frente ao armazém número 8 (oito) - berço de atracação das manobras realizadas com o uso da ferramenta de análise. Existe um trecho retilíneo, de aproximadamente uma milha e meia de extensão, balizado por 2 pares de bóias laterais, marcando um banco de menor profundidade em frente a llha das Cobras e, do outro lado, profundidades inferiores a 11 metros, em frente a llha das Enxadas.

II. As profundidades do canal em toda a extensão foram parametrizadas para o valor de 11 metros, para que não houvesse resultados erráticos de folga abaixo da quilha em virtude das diferenças de profundidade (e estes pudessem prejudicar a análise final de valores) que existem no canal de acesso ao Porto do Rio de Janeiro. Apresenta-se abaixo na figura 8 , um corte da carta náutica DHN 1512, da Diretoria de Hidrografia e Navegação (Marinha do Brasil), que ilustra o trecho do canal de acesso em que houve a parametrização de profundidades para 11 metros, e as regiões de profundidade que circundam o canal. 
VI CIDESPORT/2019

Congresso Internacional

de Desempenho Portuário
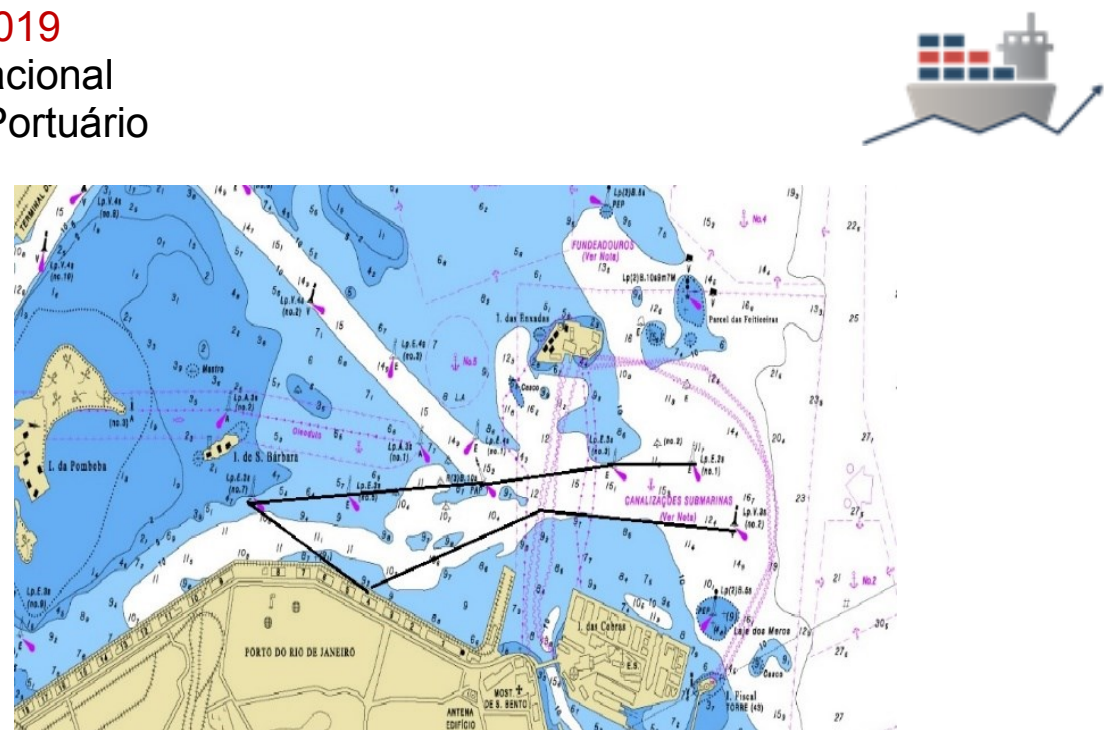

Figura 8: Trecho da carta náutica DHN 1512 com destaque para o canal de acesso ao Porto Comercial, com profundidades parametrizadas para 11,00 metros.

III. A velocidade máxima de trânsito para o navio foi limitada a 7 nós, conforme restrição imposta nas Normas e Procedimentos da Capitania dos Portos do Rio de Janeiro, NPCP-RJ, e ilustrada na figura 7 desta dissertação;

IV. Não houve cruzamentos e ultrapassagens com o navio, durante as manobras realizadas nesta análise, conforme restrições de espaço no canal de acesso, restrições estas também regulamentadas nas NPCP-RJ;

V. As manobras foram programadas com o objetivo de se utilizar a mais alta maré de enchente (preamar) de forma a permitir que navios de maiores valores de calado permitidos para o porto, graneleiros com calados de 10,90 metros, pudessem navegar pelo canal de acesso e realizar manobras de atracação, com um valor mínimo admissível de folga abaixo da quilha que não comprometesse a segurança da navegação.

\subsection{Ferramenta utilizada na análise: simulador de manobras em modelo matemático}

As análises foram executadas em um simulador de manobras que detém o software NTPro $5000 \AA$ (certificado pela DNV-GL). Este software possui o cenário escolhido, o modelo de navio graneleiro a ser utilizado, modelos de rebocadores e, condicionantes ambientais próprias do porto do Rio de Janeiro.

São empregados alguns coeficientes hidrodinâmicos validados pela empresa proprietária do software NTPro $5000 \AA$ na modelagem matemática deste simulador.

\subsection{Modelos de navios-tipo e de rebocador utilizados}

O navio-tipo utilizado nas análises, cujas principais características são mostradas na tabela 1 abaixo, foi um graneleiro com dimensões de projeto muito próximas aquelas dos navios que realizam as manobras no Porto do Rio de Janeiro. 
Tabela 1: Características do navio-tipo usado nas simulações.

\begin{tabular}{|c|c|c|c|c|c|c|}
\hline $\begin{array}{c}\text { Tipo de } \\
\text { navio }\end{array}$ & TPB & $\begin{array}{c}\text { Deslocamento } \\
\text { carregado } \\
\text { (t.m.) }\end{array}$ & $\begin{array}{c}\text { Comprimento } \\
(\mathrm{m})\end{array}$ & $\begin{array}{c}\text { Boca } \\
(\mathrm{m})\end{array}$ & $\begin{array}{c}\text { Calado } \\
(\mathrm{m})\end{array}$ & $\begin{array}{c}\text { Tipo de } \\
\text { Propulsão }\end{array}$ \\
\hline $\begin{array}{c}\text { Graneleiro } \\
\text { Classe } \\
\text { "Panamax" }\end{array}$ & 65.000 & 64062 & 225.0 & 32.3 & 10.90 & $\begin{array}{c}\text { Passo } \\
\text { Fixo }\end{array}$ \\
\hline
\end{tabular}

Adicionalmente ao navio-tipo, foram considerados modelos de rebocadores de propulsão azimutal de popa (ASD), com 40 toneladas de tração estática cada um, com características principais mostradas na tabela 2. Estas características apresentam bastante similaridade com os rebocadores portuários utilizados nas manobras reais de graneleiros de 10,90 metros de calado, no Cais Comercial do Rio de Janeiro.

Tabela 2: Características do Rebocador utilizado nas simulações.

\begin{tabular}{|c|c|c|c|c|c|}
\hline $\begin{array}{c}\text { Tipo de } \\
\text { Rebocador }\end{array}$ & $\begin{array}{c}\text { Tipo de } \\
\text { propulsão }\end{array}$ & $\begin{array}{c}\text { Tonelagem de } \\
\text { Tração } \\
\text { Estática (ton) }\end{array}$ & $\begin{array}{c}\text { Comprimento } \\
(\mathrm{m})\end{array}$ & $\begin{array}{c}\text { Boca } \\
(\mathrm{m})\end{array}$ & $\begin{array}{c}\text { Calado } \\
(\mathrm{m})\end{array}$ \\
\hline $\begin{array}{c}\text { Azimutal de } \\
\text { Popa } \\
\text { (ASD) }\end{array}$ & $\begin{array}{c}2 \\
\text { propulsores } \\
\text { azimutais } \\
\text { de passo } \\
\text { controlável }\end{array}$ & 40 & 26,10 & 8,9 & 3,3 \\
\hline
\end{tabular}

\subsection{Condições ambientais utilizadas na análise}

\subsubsection{Marés e Correntes de Maré}

As manobras foram realizadas sempre próximas a mais alta maré de enchente (preamar), adequando o valor do calado do navio-tipo (10,90 metros) as restrições impostas pela Autoridade Marítima descritas em MARINHA DO BRASIL [13].

A figura 9 mostrada abaixo representa a condição de altura de maré imposta nas simulações e pode ser interpretada da seguinte maneira: nos primeiros 30 minutos de simulação, a maré estava enchendo de uma altura de um metro e meio, até atingir o estofo de maré ${ }^{5}$ com altura de dois metros; esta condição está condizente com a máxima altura de maré astronômica mostrada na tabela 4, extraída do relatório PETROBRÁS [14].

\footnotetext{
${ }^{4}$ Deslocamento de um navio: peso total real do navio (geralmente em toneladas métricas), variável de acordo com a tonelagem de carga embarcada. Fonte: ABNT [2].

${ }^{5}$ ESTOFO DE MARÉ: Período durante o qual o nível do mar fica praticamente estacionado. Pode ser estofo de enchente ou de vazante. MIGUENS [23].
} 
VI CIDESPORT/2019

Congresso Internacional

de Desempenho Portuário

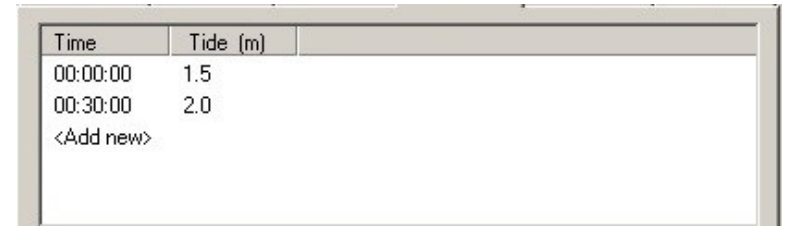

Figura 9: Condição de altura de maré inserida nas simulações.

Em relação às velocidades de correntes de maré inseridas nas análises, e, considerando que as manobras ocorreram sempre próximas a preamar, a corrente inserida nas simulações possuiu um valor próximo de zero, representando um valor mínimo de corrente de maré próximo de um estofo de maré de enchente.

$\mathrm{Na}$ análise das direções predominantes, após leitura e interpretação dos resultados do relatório PETROBRÁS [14], verificou-se que predominam as direções nordeste (NE) - para as condições de marés de vazante - e sul (S) - para as condições de marés de enchente - na região da Baía de Guanabara, cuja região do Cais Comercial do Rio de Janeiro está englobada. Estas direções podem ser representadas pela figura 10 retirada deste relatório, onde os pontos azuis indicam os vetores de corrente medidos no período analisado.

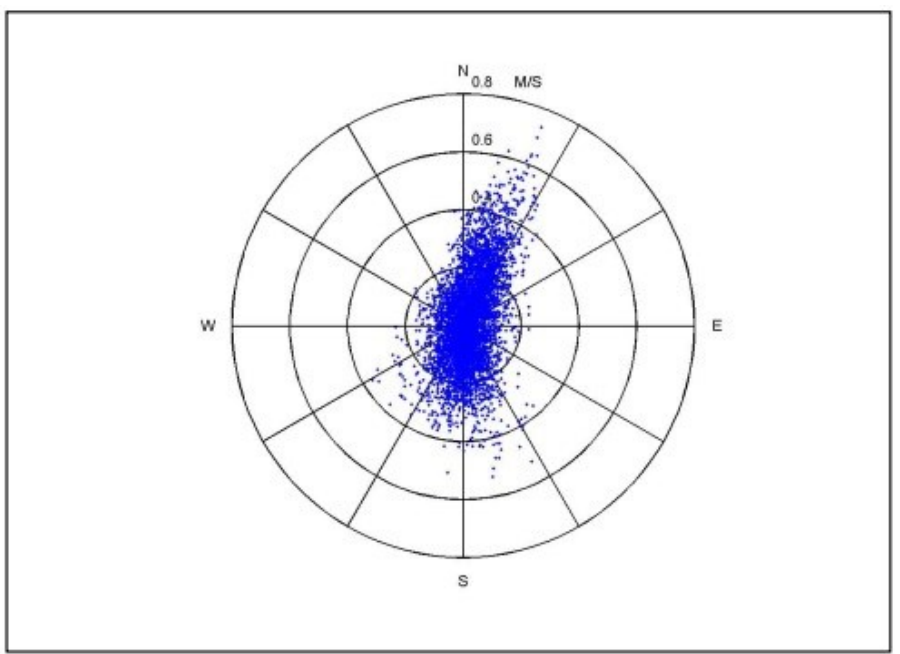

Figura 10: Imagem representando as condições predominantes de medições de corrente, durante a campanha de medições de correntes de maré. Fonte: PETROBRÁS [14].

Diante do exposto, a figura 11 representa a condição de correntes de maré inserida nas análises e pode ser interpretada da seguinte maneira: nos primeiros 30 minutos de simulação, a velocidade da corrente decresce de 0,5 (meio) nó para 0,2 (dois décimos) nós; a redução deste valor coincide com o intervalo de tempo necessário para o estofo de maré de enchente ocorre. A direção é representada pelo valor $180^{\circ}$ (cento e oitenta graus), o que representa a direção sul, significando uma condição de maré de enchente.

\begin{tabular}{|l|l|l|}
\hline Time & Current (knt) & Direction (') \\
\hline 00:00:00 & 0.5 & 180.0 \\
00:30:00 & 0.2 & 180.0 \\
〈Add new〉 & & \\
& & \\
& & \\
\end{tabular}

Figura 11: Valores de velocidade e direção de corrente de maré representada nas simulações.

\subsubsection{Regime de Ventos}


O porto utilizado na análise possui ventos predominantes de 0 (zero) até 15 nós de intensidade, e direção predominante de noroeste (NW) ou sudoeste (SW). Foram analisados os valores de vento de 0 (zero) até 15 nós de intensidade, proveniente da direção noroeste (NW), por se tratar da pior condição de manutenção do controle do navio no canal de acesso e manobras de atracação. O valor de 15 nós representa um valor limitante para as manobras de atracação neste porto, em razão da largura do canal em relação a boca do navio-tipo e espaço disponível para o navio navegar com segurança no canal de acesso, de acordo com normas da praticagem do Rio de Janeiro.

\subsubsection{Ondas}

O regime de ondas do porto analisado apresenta mar de vagas que são, de acordo com LOBO e SOARES [15], ondas formadas por vento presente; por isto, a direção das ondas acompanha a direção do vento presente, ou seja, as ondas originam-se da direção noroeste (NW) e se propagam para direção sudeste (SE). As ondas possuem períodos variando de 7 a 14 segundos de formação entre cristas, e períodos de retorno de 1, 10, 20, 30, 50 e 100 segundos.

As análises utilizaram os resultados obtidos do relatório PETROBRÁS [14], e apresentados na tabela 3 abaixo. A linha denominada "VALORES MÉDIOS" representam os valores de média aritmética de altura de onda nos diferentes períodos (7 a 14 segundos). Todos os valores são dados em metros.

Tabela 3: Valores de altura de onda (em metros) na região da Baía de Guanabara e, indicação de valores médios. Fonte: PETROBRÁS [14].

\begin{tabular}{|c|c|c|c|c|c|c|c|c|}
\hline $\operatorname{Tr} / \mathbf{T p}(\mathbf{s})$ & $\mathbf{7}$ & $\underline{\mathbf{8}}$ & $\underline{\mathbf{9}}$ & $\underline{\mathbf{1 0}}$ & $\underline{\mathbf{1 1}}$ & $\underline{\mathbf{1 2}}$ & $\underline{\mathbf{1 3}}$ & $\underline{\mathbf{1 4}}$ \\
\hline 1 & 0,22 & 0,30 & 0,66 & 0,40 & 0,51 & 0,67 & 0,99 & 1,07 \\
\hline 10 & 0,25 & 0,35 & 0,77 & 0,46 & 0,60 & 0,83 & 1,29 & 1,48 \\
\hline 20 & 0,26 & 0,36 & 0,80 & 0,48 & 0,62 & 0,86 & 1,37 & 1,59 \\
\hline 30 & 0,26 & 0,37 & 0,82 & 0,49 & 0,63 & 0,88 & 1,42 & 1,65 \\
\hline 50 & 0,26 & 0,38 & 0,84 & 0,50 & 0,64 & 0,91 & 1,47 & 1,73 \\
\hline 100 & 0,27 & 0,39 & 0,86 & 0,51 & 0,66 & 0,94 & 1,54 & 1,83 \\
\hline$\frac{\text { VALORES }}{\frac{\text { MÉDIOS }}{\mathbf{( m )}}}$ & $\mathbf{0 , 2 5}$ & $\underline{\mathbf{0 , 3 5}}$ & $\underline{\mathbf{0 , 7 9}}$ & $\underline{\mathbf{0 , 4 7}}$ & $\underline{\mathbf{0 , 6 1}}$ & $\underline{\mathbf{0 , 8 5}}$ & $\mathbf{1 , 3 5}$ & $\mathbf{1 , 5 5}$ \\
\hline
\end{tabular}

\subsubsection{Mapa das condições ambientais analisadas para obtenção de dados}

Diante das condições ambientais apresentadas nos sub-itens acima, gerou-se a tabela 4, a partir dos valores de vento (zero até 15 nós), integrados com as condições de ondas, dado que os valores de marés e corrente de marés foram fixados consoante explicação acima. 


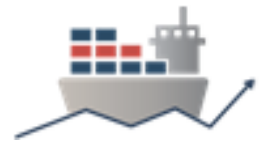

Tabela 4: Quadro-resumo das condições ambientais utilizado na análise.

\begin{tabular}{|c|c|c|c|c|c|c|c|c|}
\hline $\begin{array}{l}\text { Condição da } \\
\text { Onda / } \\
\text { Veloc. Do } \\
\text { Vento }\end{array}$ & $\begin{array}{c}\text { Cond.1 } \\
\text { Altura } \\
\text { (m): } \\
0,25 \\
\text { Período } \\
\text { (s): } \\
7\end{array}$ & $\begin{array}{c}\text { Cond.2 } \\
\text { Altura } \\
\text { (m): } \\
0,35 \\
\text { Período } \\
\text { (s): } \\
8\end{array}$ & $\begin{array}{c}\text { Cond.3 } \\
\text { Altura } \\
\text { (m): } \\
0,79 \\
\text { Período } \\
\text { (s) } \\
9\end{array}$ & $\begin{array}{c}\text { Cond.4 } \\
\text { Altura } \\
\text { (m): } \\
0,47 \\
\text { Período } \\
\text { (s) } \\
10\end{array}$ & $\begin{array}{c}\text { Cond.5 } \\
\text { Altura } \\
\text { (m): } \\
0,61 \\
\text { Período } \\
\text { (s) } \\
11\end{array}$ & $\begin{array}{c}\text { Cond.6 } \\
\text { Altura } \\
\text { (m): } \\
0,85 \\
\text { Período } \\
\text { (s) } \\
12\end{array}$ & $\begin{array}{c}\text { Cond.7 } \\
\text { Altura } \\
\text { (m): } \\
1,35 \\
\text { Período } \\
\text { (s) } \\
13\end{array}$ & $\begin{array}{c}\text { Cond.8 } \\
\text { Altura } \\
\text { (m): } \\
1,55 \\
\text { Período } \\
\text { (s) } \\
14\end{array}$ \\
\hline $\begin{array}{c}\text { Vento (nós): } \\
0 \\
\downarrow \\
15\end{array}$ & \multicolumn{8}{|c|}{$\begin{array}{c}\text { Valores encontrados de Folga Abaixo da Quilha (em metros), de acordo com o } \\
\text { número de rebocadores, a partir das simulações realizadas. }\end{array}$} \\
\hline
\end{tabular}

\section{SIMULAÇÕES E DISCUSSÃO DOS RESULTADOS}

As manobras deste estudo de caso focaram em analisar a pior condição para afundamento do navio em velocidade, devido aos efeitos apresentados e explicados no item 3 (squat, afundamento em ondas e inclinação dinâmica), para um porto de exportação de carga a granel. Em vista disso, foram realizadas simulações de manobras de atracação do navio-tipo e rebocadores, sob os diferentes cenários ambientais apresentados na tabela 4.

Ressalta-se que o cenário do estudo foi um canal de acesso modelado com uma profundidade única de 11 metros em toda a sua extensão até a região do berço de atracação, evitando que diferentes valores de profundidades do canal de acesso ao porto do Rio de Janeiro levassem a resultados erráticos de folga abaixo da quilha.

Para efeito de simplificação e melhoria da compreensão dos resultados, as condições ambientais da tabela 4 foram renomeadas para condição de ondas (variando de 1 até 8 ) versus condição de vento (variando de 0 até 15). Dessa forma, a condição denominada, por exemplo, "4.10", significa a condição 4 de mar - ondas de 0,47 metros e período de 10 segundos - e vento de 10 nós.

\subsection{Valores de folga abaixo da quilha nas manobras com 2 rebocadores, e velocidades médias de 6 a 7 nós}

Para obtenção dos valores mínimos de folga abaixo da quilha com a utilização de 2 rebocadores, foram realizadas 90 simulações de manobras de atracação do navio-tipo, nas condições ambientais descritas na tabela 4.

Todas as simulações foram realizadas com o navio-tipo navegando no piloto automático até próximo do berço de atracação; ou seja, não foi empregado fator humano nas manobras, para compensar as forças de vento, corrente e ondas e atuação destas no navio-tipo.

Cada simulação com 2 rebocadores durou em média de 20 a 40 minutos; as simulações ocorreram com o navio-tipo navegando a uma velocidade média entre 6 a 7 nós, dentro do canal de acesso (próximo das bóias 1 e 2), sem o auxílio de rebocadores. As condições foram impostas para que o navio-tipo reduzisse sua velocidade para 5 nós, apenas para que os rebocadores se aproximassem e amarrassem os cabos ao navio-tipo. Este é um valor seguro de velocidade preconizado pela IMO MSC. Circ. $1101^{6}$ e por HENSEN [1], que o navio-tipo deve ter

${ }^{6}$ IMO Circ. 1101. SHIP PORT INTERFACE. Availability of Tug Assistance. 2003 
para os rebocadores façam a aproximação e minimizem os efeitos indesejáveis de interação navio-rebocador, que podem ser causa de acidentes.

A tabela 5 a seguir apresenta os valores mínimos de folga abaixo da quilha obtidos após todas as 90 (noventa) simulações realizadas com 2 (dois) rebocadores:

Tabela 5: Valores mínimos (em metros) encontrados de folga abaixo da quilha nas simulações com 2 rebocadores.

\begin{tabular}{|c|c|c|c|c|c|c|c|c|}
\hline $\begin{array}{l}\text { Onda / } \\
\text { Veloc. Do } \\
\text { Vento } \\
\text { (nós) }\end{array}$ & $\begin{array}{c}\text { Cond.1 } \\
\text { Altura } \\
\text { (m): } \\
0,25 \\
\text { Período } \\
\text { (s): } \\
7\end{array}$ & $\begin{array}{c}\text { Cond.2 } \\
\text { Altura } \\
(\mathrm{m}): \\
0,35 \\
\text { Período } \\
\text { (s): } \\
8\end{array}$ & $\begin{array}{l}\text { Cond.3 } \\
\text { Altura } \\
\text { (m): } \\
0,79 \\
\text { Período } \\
\text { (s) } \\
9\end{array}$ & $\begin{array}{c}\text { Cond.4 } \\
\text { Altura } \\
(\mathrm{m}): \\
0,47 \\
\text { Período } \\
\text { (s) } \\
10\end{array}$ & $\begin{array}{l}\text { Cond.5 } \\
\text { Altura } \\
\text { (m): } \\
0,61 \\
\text { Período } \\
\text { (s) } \\
11\end{array}$ & $\begin{array}{c}\text { Cond.6 } \\
\text { Altura } \\
(\mathrm{m}): \\
0,85 \\
\text { Período } \\
\text { (s) } \\
12\end{array}$ & $\begin{array}{c}\text { Cond.7 } \\
\text { Altura } \\
\text { (m): } \\
1,35 \\
\text { Período } \\
\text { (s) } \\
13\end{array}$ & $\begin{array}{c}\text { Cond.8 } \\
\text { Altura } \\
\text { (m): } \\
1,55 \\
\text { Período } \\
\text { (s) } \\
14\end{array}$ \\
\hline 0 & 0,487 & 0,485 & 0,467 & 0,717 & 0.574 & 0,707 & 0,692 & 0,699 \\
\hline 1 & 0,498 & 0,467 & 0,463 & 0,692 & 0,588 & 0,723 & 0,667 & 0,718 \\
\hline 2 & 0,522 & 0,489 & 0,522 & 0,723 & 0,687 & 0,729 & 0,682 & 0,741 \\
\hline 3 & 0,567 & 0,488 & 0,560 & 0,747 & 0,652 & 0,741 & 0,679 & 0,727 \\
\hline 4 & 0,502 & 0,492 & 0,501 & 0,762 & 0,723 & 0,737 & 0,613 & 0,732 \\
\hline 5 & 0,490 & 0,462 & 0,522 & 0,720 & 0,774 & 0,716 & 0,603 & 0,720 \\
\hline 6 & 0,515 & 0,457 & 0,489 & 0,763 & 0,778 & 0,723 & 0,627 & 0,739 \\
\hline 7 & 0,517 & 0,468 & 0,499 & 0,759 & 0,798 & 0,709 & 0,653 & 0,728 \\
\hline 8 & 0,505 & 0,472 & 0,472 & 0,789 & 0,789 & 0,672 & 0,647 & 0,735 \\
\hline 9 & 0,501 & 0,489 & 0,479 & 0,770 & 0,752 & 0,668 & 0,659 & 0,742 \\
\hline 10 & 0,498 & 0,561 & 0,463 & 0,723 & 0,789 & 0,626 & 0,664 & 0,738 \\
\hline 11 & 0,487 & 0,582 & 0,458 & 0,784 & 0,780 & 0,675 & 0,688 & 0,731 \\
\hline 12 & 0,492 & 0,438 & 0,461 & 0,763 & 0,761 & 0,687 & 0,672 & 0,769 \\
\hline 13 & 0,499 & 0,440 & 0,453 & 0,781 & 0,779 & 0,654 & 0,637 & 0,758 \\
\hline 14 & 0,501 & 0,431 & 0,452 & 0,792 & 0,753 & 0,702 & 0,642 & 0,780 \\
\hline 15 & 0,523 & 0,440 & 0,440 & 0,712 & 0,749 & 0,716 & 0,635 & 0,778 \\
\hline
\end{tabular}

A premissa nesta fase inicial de coleta de dados é que os rebocadores não serão utilizados para reduzir a velocidade do navio-tipo; sua atuação junto ao navio ocorre apenas no controle do seu aproamento e manutenção do seu curso retilíneo no canal de acesso.

Para cada simulação, são obtidos dados em uma planilha dos valores de folga abaixo da quilha no domínio do tempo, em intervalos de tempo regulares de 10 (dez) em 10 (dez) segundos. As figuras 12 e 13 abaixo apresentam os gráficos representativos das medições de folga abaixo da quilha e do decréscimo de velocidade no domínio do tempo, na condição "8.15", em que se obteve o valor máximo de folga abaixo da quilha registrada. 


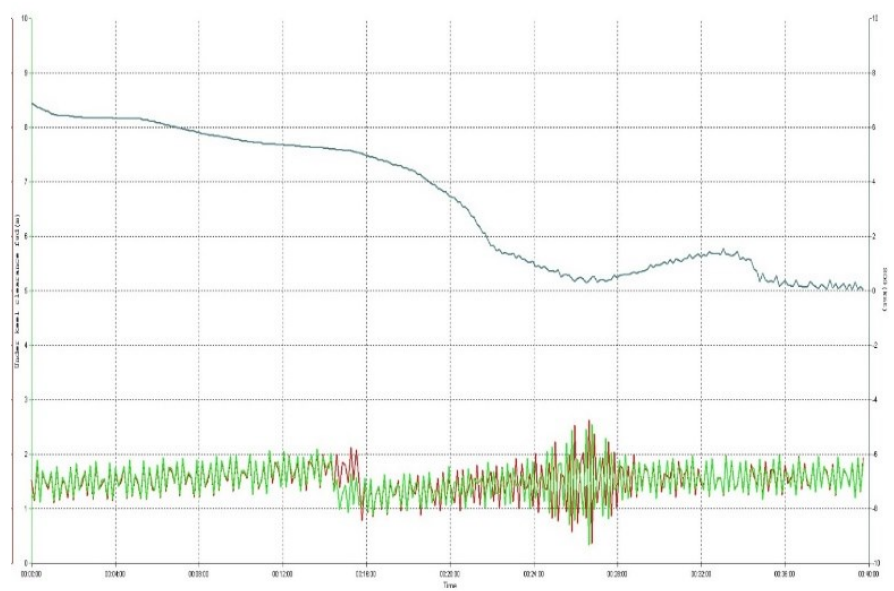

Figura 12: Variação dos valores de folga abaixo da quilha e velocidade do navio no domínio do tempo, de acordo com os valores obtidos na manobra com 2 rebocadores na condição " 8.15 ".

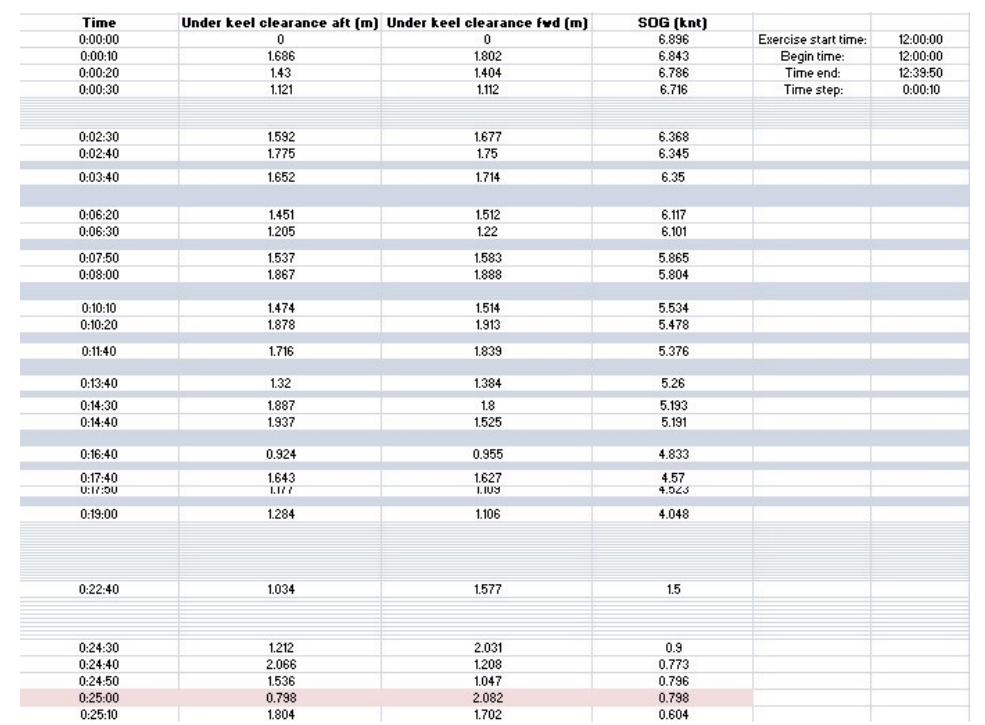

Figura 13: Trecho da planilha de dados (Excel) mostrando os valores obtidos de folga abaixo da quilha e velocidade do navio, no domínio do tempo: manobra com 2 rebocadores, na condição "8.15".

Após análise da tabela 5 , verifica-se que os valores de folga abaixo da quilha encontrados decrescem conforme a condição de mar fica menos severa, isto é, quanto menor a altura e períodos da onda incidente no navio, menores serão os valores encontrados. Isto pode ser identificado facilmente pelos dados obtidos nas condições "1", "2" e "3", cujos valores encontrados são bem inferiores aos das condições "7" e "8" (condições mais severas de mar). Atribui-se a esta redução ao fato do navio-tipo ter o seu curso retilíneo menos perturbado no canal de acesso quando a onda incidente tiver menores alturas e períodos.

Dessa forma, se ele consegue manter o curso no canal sem maiores perturbações da onda incidente, o navio navegará com uma velocidade mais próxima da velocidade pré-estabelecida (6 a 7 nós), fato que aumentará seus valores de afundamento devido a squat e ondas, consoante explicações do capítulo 1 deste trabalho.

Apresenta-se a figura 14 a seguir a trajetória percorrida pelo navio-tipo na manobra com 2 rebocadores na condição "8.15". Nota-se que o navio percorre uma trajetória retilínea no rumo de aproximação pelo canal, faz uma guinada para 
bombordo (bordo esquerdo) da sua trajetória para adentrar na área mais abrigada do porto, e, já neste local, percorre novamente uma trajetória retilínea. Apresenta-se também a direção relativa do mar e vento, demonstrando uma angulação incidente de aproximadamente $30^{\circ}$ a $45^{\circ}$ com o curso (rumo) do navio no canal.

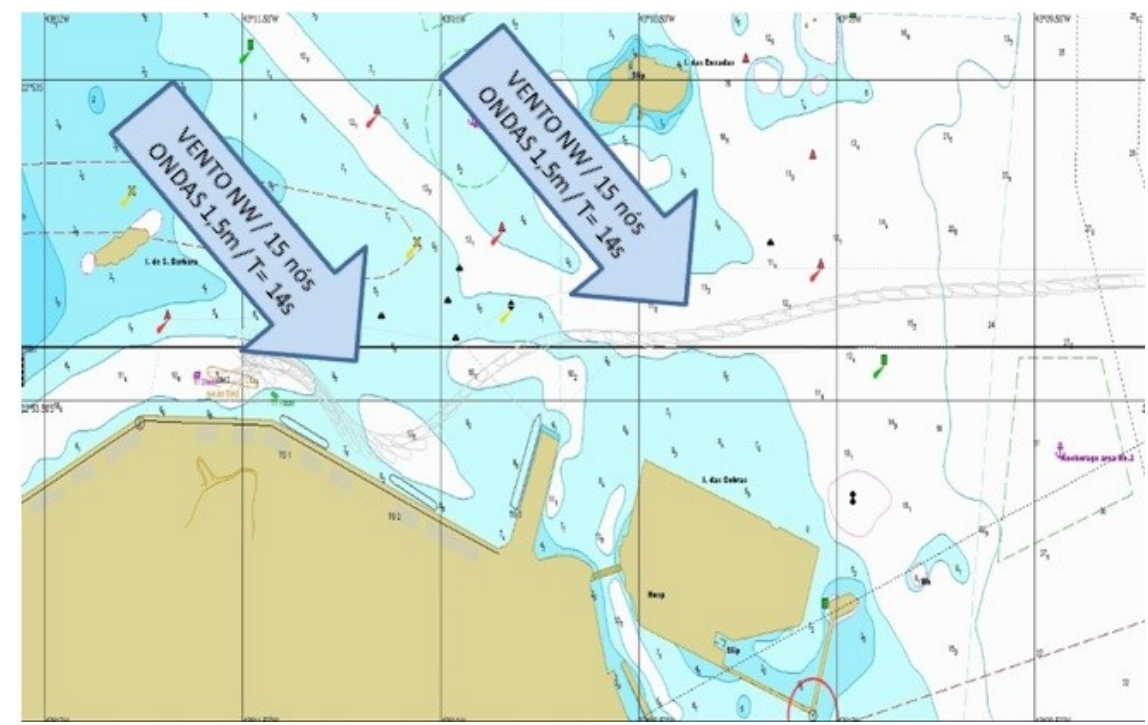

Figura 14: Trajetória percorrida pelo navio-tipo durante uma manobra de atracação com 2 rebocadores, na condição "8.15".

Em acréscimo a explicação acima, o valor elevado de intensidade do vento nesta manobra - 15 nós - em conjunto com sua direção relativa de incidência no navio - aproximadamente $30^{\circ} \mathrm{com}$ o aproamento do navio em grande parte do canal de acesso - faz com que haja aumento da resistência ao avanço do navio, conforme ensina LARSSON, et al [16]. Este aumento de resistência ao avanço faz com que a redução de velocidade do navio seja mínima, resultando em valores mínimos de afundamento devido a efeito Squat e ondas.

\subsection{Valores de folga abaixo da quilha nas manobras com 5 rebocadores, e velocidades médias de 3 a 4 nós.}

Para obtenção dos valores mínimos de folga abaixo da quilha com a utilização de 5 rebocadores, foram realizadas outras 90 simulações de manobras de atracação do navio-tipo, nas condições ambientais descritas já especificadas.

Cada simulação com 5 rebocadores durou em média de 50 minutos a 1 hora, já que navio-tipo navegou a uma velocidade média em torno de 3 a 4 nós, dentro do canal de acesso (próximo das bóias 1 e 2), com auxílio total dos rebocadores. A partir do momento que os rebocadores são amarrados ao navio, como pode ser visualizado na figura 15, retirada de uma das simulações, os rebocadores passam a rebocar o navio a uma velocidade próxima de 3 a 4 nós, segundo o método combinado ${ }^{7}$ de manobra.

\footnotetext{
7 Segundo HENSEN [1], o método combinado é uma combinação de 2 (dois) outros conhecidos métodos de utilizar rebocadores auxiliando os navios em trânsito. Consiste em utilizar rebocadores amarrados ao costado do navio (método americano) e também operando com cabo longo (método europeu).
} 
VI CIDESPORT/2019

Congresso Internacional

de Desempenho Portuário
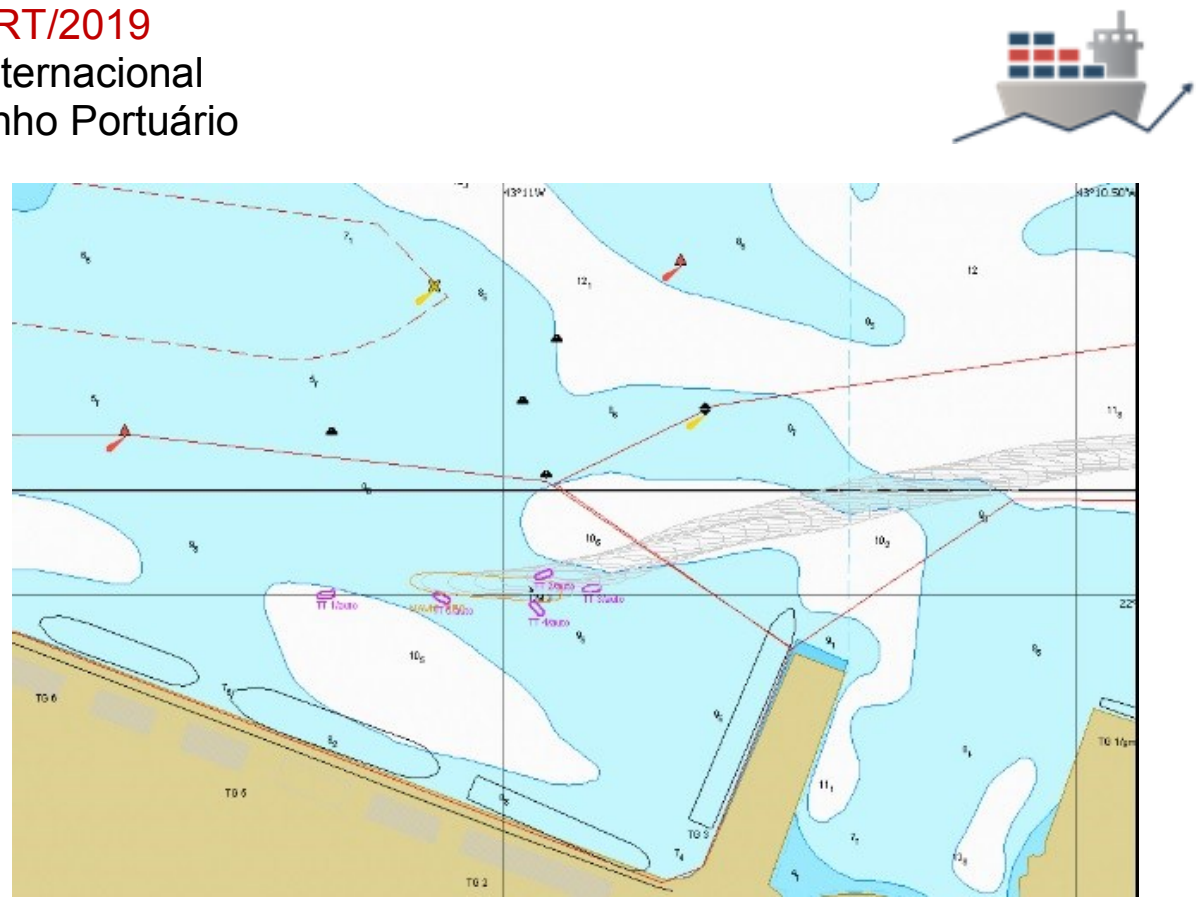

Figura 15: Imagem aérea de uma das simulações feitas com 5 rebocadores. Condição "3.10".

A tabela 6 a seguir apresenta os valores mínimos de folga abaixo da quilha obtidos após todas as 90 (noventa) simulações realizadas com 5 rebocadores:

Tabela 6: Valores mínimos (em metros) encontrados de folga abaixo da quilha nas simulações com 5 rebocadores.

\begin{tabular}{|c|c|c|c|c|c|c|c|c|}
\hline $\begin{array}{c}\text { Onda } \\
/ \\
\text { Veloc. } \\
\text { Do } \\
\text { Vento } \\
\text { (nós) }\end{array}$ & $\begin{array}{c}\text { Cond.1 } \\
\text { Altura } \\
\text { (m): } \\
0,25 \\
\text { Período } \\
\text { (s): } \\
7\end{array}$ & $\begin{array}{c}\text { Cond.2 } \\
\text { Altura } \\
\text { (m): } \\
0,35 \\
\text { Período } \\
\text { (s): } \\
8 \\
\end{array}$ & $\begin{array}{c}\text { Cond.3 } \\
\text { Altura } \\
\text { (m): } \\
0,79 \\
\text { Período } \\
\text { (s) } \\
9 \\
\end{array}$ & $\begin{array}{c}\text { Cond.4 } \\
\text { Altura } \\
\text { (m): } \\
0,47 \\
\text { Período } \\
\text { (s) } \\
10 \\
\end{array}$ & $\begin{array}{c}\text { Cond.5 } \\
\text { Altura } \\
\text { (m): } \\
0,61 \\
\text { Período } \\
\text { (s) } \\
11 \\
\end{array}$ & $\begin{array}{c}\text { Cond.6 } \\
\text { Altura } \\
\text { (m): } \\
0,85 \\
\text { Período } \\
\text { (s) } \\
12 \\
\end{array}$ & $\begin{array}{c}\text { Cond.7 } \\
\text { Altura } \\
\text { (m): } \\
1,35 \\
\text { Período } \\
\text { (s) } \\
13 \\
\end{array}$ & $\begin{array}{c}\text { Cond.8 } \\
\text { Altura } \\
\text { (m): } \\
1,55 \\
\text { Período } \\
\text { (s) } \\
14 \\
\end{array}$ \\
\hline 0 & 0,749 & 1,074 & 1,003 & 1,063 & 1,044 & 0,932 & 0,807 & 0,776 \\
\hline 1 & 0,781 & 1,088 & 1,012 & 1,084 & 1,038 & 0,957 & 0,812 & 0,787 \\
\hline 2 & 0,698 & 1,069 & 1,029 & 1,079 & 1, & 0,969 & 13 & 0,791 \\
\hline 3 & 0,724 & 1,070 & 1,018 & 1,088 & 1,021 & 0,978 & 0,819 & 0,774 \\
\hline 4 & 0,763 & 1,043 & 1,017 & 1,082 & 1,029 & 0,991 & 0,817 & 0,781 \\
\hline 5 & 0,601 & 1,065 & 1,013 & 1,086 & 1,019 & 0,997 & 0,815 & 0,785 \\
\hline 6 & 0,698 & 1,054 & 1,020 & 1,073 & 1,038 & 0,969 & 0,839 & 0,787 \\
\hline 7 & 0,789 & 1,095 & 1,031 & 1,077 & 1,031 & 0,987 & 0,829 & 0,789 \\
\hline 8 & 0,942 & 1,099 & 1,027 & 1,080 & 1,049 & 0,961 & 0,845 & 0,780 \\
\hline 9 & 0,957 & 1,071 & 1,017 & 1,081 & 1,051 & 0,959 & 0,879 & 0,791 \\
\hline 10 & 1,140 & 1,076 & 1,023 & 1,076 & 1,056 & 0,956 & 0,841 & 0,788 \\
\hline 11 & 1,102 & 1,051 & 1,019 & 1,089 & 1,047 & 0,949 & 0,849 & 0,791 \\
\hline 12 & 1,154 & 1,039 & 1,021 & 1,110 & 1,029 & 0,952 & 0,853 & 0,811 \\
\hline 13 & 1,110 & 1,011 & 1,028 & 1,117 & 1,013 & 0,955 & 0,929 & 0,805 \\
\hline 14 & 1,218 & 1,024 & 1,009 & 1,113 & 1,028 & 0,959 & 0,957 & 0,817 \\
\hline 15 & 1,168 & 1,004 & 1,002 & 1,149 & 1,009 & 0,956 & 0,960 & 0,819 \\
\hline
\end{tabular}

Da mesma forma que nas primeiras 90 simulações realizadas, foram gerados novos dados (também em planilhas) de folga abaixo da quilha e velocidade, em intervalos de tempo regulares de 10 (dez) em 10 (dez) segundos. 
Nota-se que, para a mesma condição de mar (a exceção da condição "1"), as manobras com 5 rebocadores apresentam dados de folga abaixo da quilha muito próximos uns dos outros. Isto se deve ao fato de não ter havido muitas diferenças de velocidade média do navio, e este ter seguido um curso quase retilíneo no canal de acesso, evitando interação com as regiões rasas adjacentes a ele. Este controle no governo do navio no canal de acesso, na maior parte do tempo, foi possível pela inclusão de um número maior de rebocadores.

A figura 16 apresenta um gráfico representativo das medições de folga abaixo da quilha e do decréscimo de velocidade do navio-tipo. O tempo de manobra foi de aproximadamente 70 minutos (1 hora e 10 minutos).

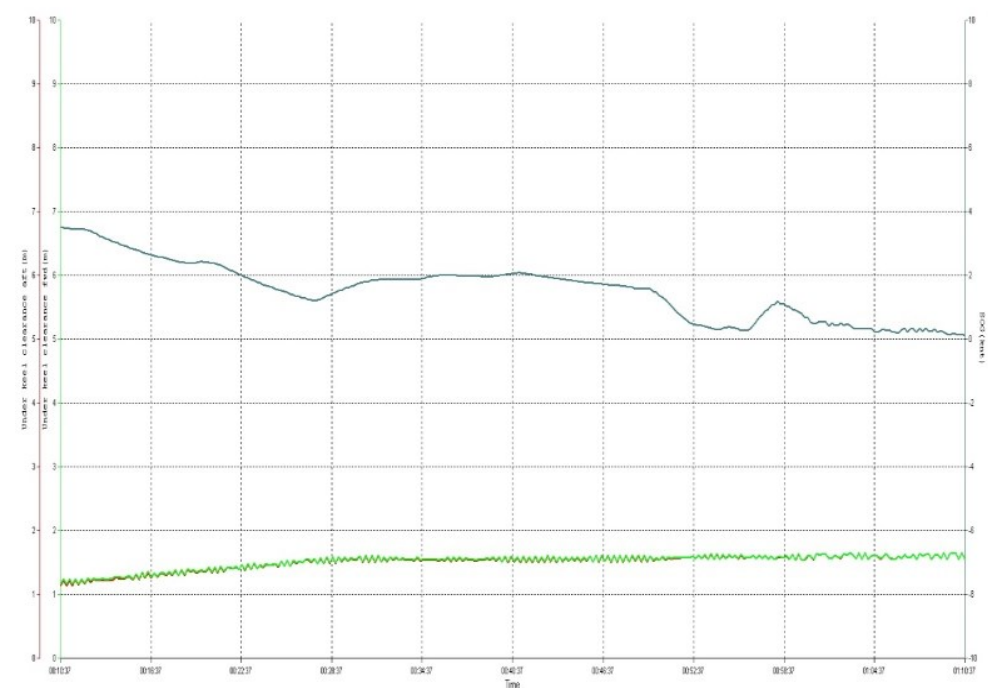

Figura 16: Variação dos valores de folga abaixo da quilha e velocidade do navio no domínio do tempo, de acordo com os valores obtidos na manobra com 5 rebocadores, na condição "1.14".

Diante do exposto na proposta do artigo, a seguir será abordado os cálculos das diferenças de folga abaixo da quilha para cada uma das 90 análises. A partir destas diferenças, será apresentado um "trade-off" entre o aumento de receita pelo embarque de carga devido a esta diferença de folga abaixo da quilha (convertida em aumento de calado para o navio), e incremento do custo em razão do aumento do número de rebocadores na manobra.

\section{ANÁLISE ECONOMICA DA OPERAÇÃO}

\subsection{Cálculo da quantidade de carga a ser embarcada}

Após as 180 simulações realizadas, que apresentaram os valores mínimos de folga abaixo da quilha em cada simulação e, com as comparações dos resultados mostrados nas tabelas 5 e 6, pode-se afirmar que em algumas condições ambientais para as manobras específicas e para o porto analisado, houve significativas diferenças de folga abaixo da quilha através da inclusão de 3 rebocadores na manobra. Por outro lado, em outras condições ambientais do estudo, estas diferenças não foram relevantes, e o incremento do custo pela inclusão de 3 rebocadores pode não compensar financeiramente as receitas obtidas.

Dessa forma, a tabela 7 mostrada a seguir apresenta as diferenças entre os dados de folga abaixo da quilha obtidos pelas tabelas 5 e 6 , respectivamente manobras com 5 e 2 rebocadores. 
Tabela 7: Valores mínimos (em metros) encontrados de folga abaixo da quilha nas simulações com 5 rebocadores.

\begin{tabular}{|c|c|c|c|c|c|c|c|c|}
\hline $\begin{array}{l}\text { Onda / } \\
\text { Veloc. do } \\
\text { Vento } \\
\text { (nós) }\end{array}$ & $\begin{array}{c}\text { Cond.1 } \\
\text { Altura } \\
\text { (m): } \\
0,25 \\
\text { Período } \\
\text { (s): } \\
7\end{array}$ & $\begin{array}{c}\text { Cond.2 } \\
\text { Altura } \\
\text { (m): } \\
0,35 \\
\text { Período } \\
\text { (s): } \\
8\end{array}$ & $\begin{array}{c}\text { Cond.3 } \\
\text { Altura } \\
\text { (m): } \\
0,79 \\
\text { Período } \\
\text { (s) } \\
9\end{array}$ & $\begin{array}{c}\text { Cond.4 } \\
\text { Altura } \\
\text { (m): } \\
0,47 \\
\text { Período } \\
\text { (s) } \\
10\end{array}$ & $\begin{array}{c}\text { Cond.5 } \\
\text { Altura } \\
\text { (m): } \\
0,61 \\
\text { Período } \\
\text { (s) } \\
11\end{array}$ & $\begin{array}{c}\text { Cond.6 } \\
\text { Altura } \\
(\mathrm{m}): \\
0,85 \\
\text { Período } \\
\text { (s) } \\
12\end{array}$ & $\begin{array}{c}\text { Cond.7 } \\
\text { Altura } \\
\text { (m): } \\
1,35 \\
\text { Período } \\
\text { (s) } \\
13\end{array}$ & $\begin{array}{c}\text { Cond.8 } \\
\text { Altura } \\
\text { (m): } \\
1,55 \\
\text { Período } \\
\text { (s) } \\
14\end{array}$ \\
\hline 0 & 0,262 & 0,589 & 0,536 & 0,346 & 0,470 & 0,225 & 0,115 & 0,077 \\
\hline 1 & 0,283 & 0,621 & 0,549 & 0,392 & 0,450 & 0,234 & 0,145 & 0,069 \\
\hline 2 & 0,176 & 0,580 & 0,507 & 0,356 & 0,345 & 0,240 & 0,131 & 0,050 \\
\hline 3 & 0,157 & 0,582 & 0,458 & 0,341 & 0,369 & 0,237 & 0,140 & 0,047 \\
\hline 4 & 0,261 & 0,551 & 0,516 & 0,320 & 0,306 & 0,254 & 0,204 & 0,049 \\
\hline 5 & 0,111 & 0,603 & 0,491 & 0,366 & 0,245 & 0,281 & 0,212 & 0,065 \\
\hline 6 & 0,183 & 0,597 & 0,531 & 0,310 & 0,260 & 0,246 & 0,212 & 0,048 \\
\hline 7 & 0,272 & 0,627 & 0,532 & 0,318 & 0,253 & 0,278 & 0,176 & 0,061 \\
\hline 8 & 0,437 & 0,627 & 0,555 & 0,291 & 0,260 & 0,289 & 0,198 & 0,045 \\
\hline 9 & 0,456 & 0,582 & 0,538 & 0,311 & 0,299 & 0,291 & 0,220 & 0,049 \\
\hline 10 & 0,642 & 0,515 & 0,560 & 0,353 & 0,267 & 0,330 & 0,177 & 0,050 \\
\hline 11 & 0,615 & 0,469 & 0,561 & 0,305 & 0,267 & 0,274 & 0,161 & 0,060 \\
\hline 12 & 0,662 & 0,601 & 0,560 & 0,347 & 0,268 & 0,265 & 0,181 & 0,042 \\
\hline 13 & 0,611 & 0,571 & 0,575 & 0,336 & 0,234 & 0,301 & 0,292 & 0,047 \\
\hline 14 & 0,717 & 0,593 & 0,557 & 0,321 & 0,275 & 0,257 & 0,315 & 0,037 \\
\hline 15 & 0,645 & 0,564 & 0,562 & 0,437 & 0,260 & 0,240 & 0,325 & 0,021 \\
\hline$\frac{\text { VALORES }}{\text { MÉDIOS }}$ & 0,360 & 0,586 & 0,544 & 0,339 & 0,268 & 0,261 & 0,190 & 0,049 \\
\hline
\end{tabular}

A coluna "VALORES MÉDIOS" indica a média aritmética entre os 15 dados obtidos em cada coluna de condição de mar. Nota-se que os valores vão decrescendo a partir da condição "2". Em vista disso, algumas conclusões, a priori, podem ser extraídas:

I. O valor mínimo encontrado, que representa a menor diferença de folga abaixo da quilha através da inclusão de 3 rebocadores na manobra, ocorreu na condição "8.15", foi de 0,021 metros.Conforme pode ser visto pela comparação dos dados das tabelas 6 e 7, os resultados de folga abaixo da quilha encontrados são muito próximos na condição "8", para cada condição estabelecida ("8.1", "8.2", e assim por diante). A razão deste resultado, já comentada neste artigo,pode ser atribuída aos valores de velocidade média do navio não terem apresentado muitas diferenças, quando comparadas as análises que utilizaram 5 rebocadores, com aquelas que utilizaram 2 rebocadores.

II. O valor máximo encontrado, representando a maior diferença de folga abaixo da quilha através da inclusão de 3 rebocadores na manobra, ocorreu na condição "1.14", foi de 0,717 metros.

Conforme já explicado neste artigo, a manobra com 5 rebocadores na condição "1.14" foi feita sob uma velocidade média de 2,2 nós, em que o navio-tipo conseguiu navegar de forma segura no canal com a assistência de 5 rebocadores. Esta velocidade causou uma redução significativa dos efeitos de afundamento em ondas, e do efeito Squat, gerando um valor de folga abaixo da quilha de 1,218 metros. 
Em vista disso, esta foi a análise que gerou a maior diferença entre os valores encontrados nas simulações com 5 rebocadores face as simulações que utilizaram 2 rebocadores, indo ao encontro também da conclusão exposta no item abaixo.

III. De forma geral, a inclusão de 3 rebocadores gerou maiores diferenças de folga abaixo da quilha nas condições ambientais menos severas, por exemplo, condições "2" e "3" de mar.

Alinhada com a conclusão exposta no item II acima, os resultados demonstram também que as maiores diferenças entre os valores médios de folga abaixo da quilha ocorreram em condições moderadas de mar: condições "2" e "3". Pode-se atribuir isto ao fato da redução de velocidade média ter sido mais significativa nestas condições, sem afetar o curso do navio no canal de acesso e sem permitir que o navio se aproximasse das margens.

IV. A inclusão de 3 rebocadores na manobra do navio-tipo não alterou significativamente a folga abaixo da quilha nas condições ambientais mais severas de mar, por exemplo, condições "7" e "8".

Nas manobras com 5 rebocadores realizadas sob condições ambientais mais severas, não houve redução substancial da velocidade média do navio em relação as manobras com 2 rebocadores. Entretanto, houve alguns momentos da travessia no canal de acesso que foi necessário o aumento da velocidade para tornar o curso do navio mais retilíneo e afastá-lo das áreas rasas adjacentes ao canal, exatamente porque o efeito da condição de mar e vento (combinados) sobre o navio em movimento é tender afastá-lo do centro do canal.

Como os dados apresentados na tabela 8 apresentam os valores mínimos encontrados, nestes instantes que os rebocadores imprimiram ao navio-tipo uma maior velocidade para evitar aproximação de margens (ou possível encalhe), registrou-se os menores valores de folga abaixo da quilha, e estes valores são bem próximos daqueles obtidos na tabela 7, para as condições ambientais mais severas.

Para obtenção da capacidade de carga possível a ser embarcada a partir destas diferenças de folga abaixo da quilha convertidas em aumento de calado, é necessário conhecer o dado do TPC (toneladas por centímetro de imersão) do navio para o calado de 10,90 metros. Para isto, utilizou-se um manual de trim e estabilidade de um navio graneleiro classe "Panamax", retirado de VEROLME [17], cujas características são apresentadas na tabela 8 a seguir:

Tabela 8: Dados reais de navio graneleiro da classe "Panamax".

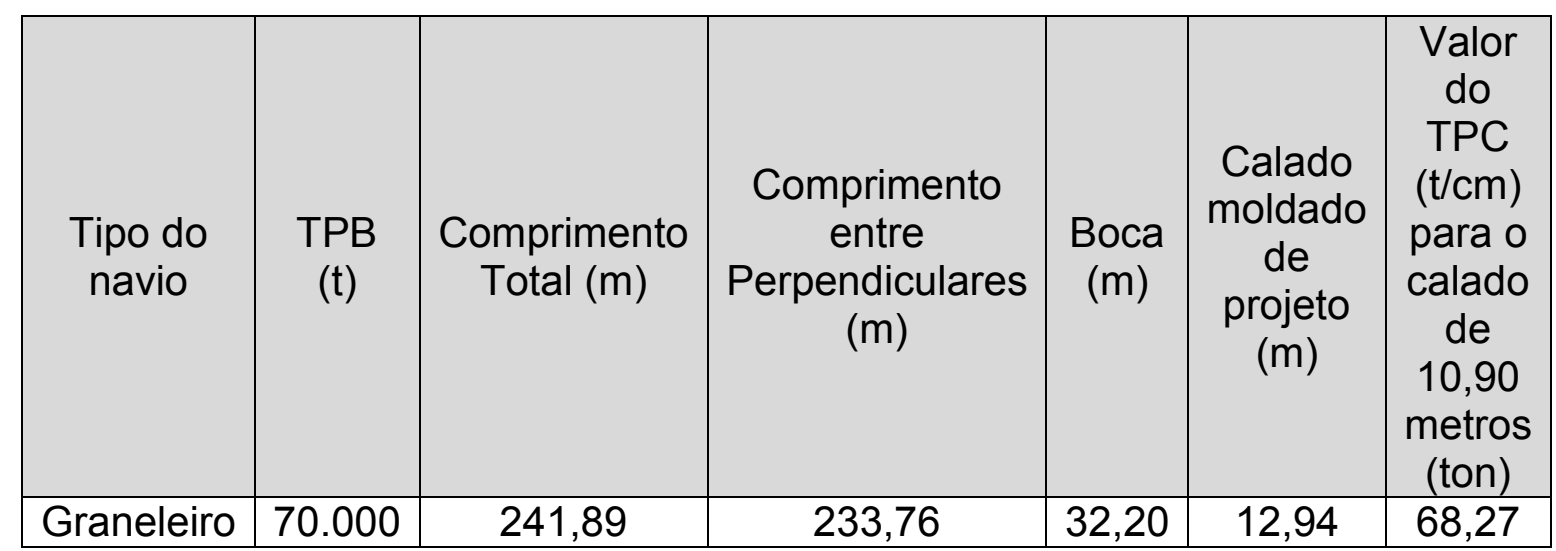




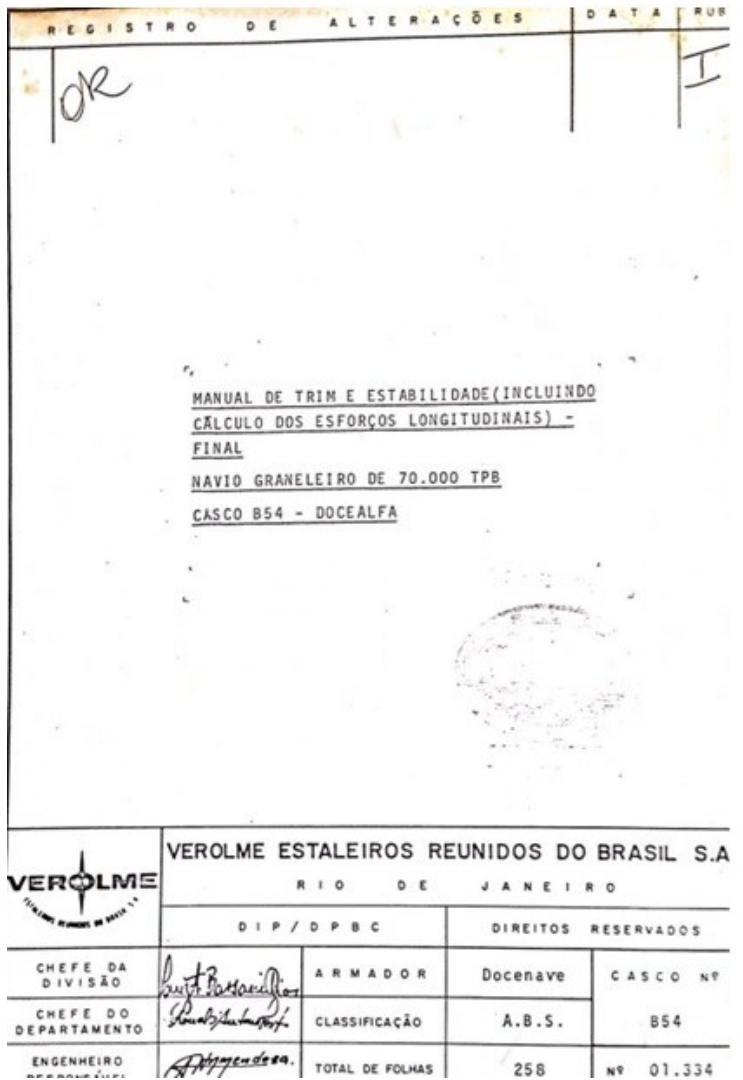

\begin{tabular}{|c|c|c|c|c|c|c|c|}
\hline & & 401 & $k=$ & t & Asn. & & 6 \\
\hline & CAP & $\overline{C T E}$ & ICAS & HIOROS & TTATICAS & & \\
\hline $\begin{array}{c}\text { CAL NoO } \\
\text { EXTRE } \\
\text { int }\end{array}$ & \begin{tabular}{|c} 
oesrocunerto \\
TOtAL \\
in
\end{tabular} & $\begin{array}{c}\text { PORTE } \\
\text { oRUTO } \\
\text { i" }\end{array}$ & TPC & אר & 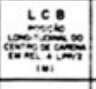 & 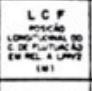 & $\begin{array}{l}\text { We } \\
\text { IE. } \\
\end{array}$ \\
\hline 8,00 & 50714 & 37434 & -66.52 & -16.37 & -5.72 & 3.69 & . \\
\hline 0.20 & 51379 & 38099 & $-66,56$ & 14,30 & $-5,69$ & $-3,62$ & 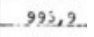 \\
\hline 8,20 & 52045 & 38765 & 66,61 & 14,23 & $-5,67$ & $-3,55$ & 997,9 \\
\hline 8,30 & 52711. & 394 & 66,65 & 14,26 & $-5,64$ & $-3,48$ & 99. \\
\hline 8,40 & 53378 & 40098 & 66,70 & 14,10 & -5.61 & $-3,42$ & -1002 \\
\hline 8,50 & 54045 & 40765 & 66,74 & 14,04 & -5.59 & $-3,37$ & 2602. \\
\hline 3,60 & 54713 & .41433 & 66,77 & 13,98 & $-5,56$ & $-3,31$ & 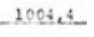 \\
\hline 8,70 & 55336 & 42100 & $-66,82$ & -13.22 & -5.52 & -3.25 & 2002 \\
\hline 8,80 & 5604 & -4276 & 66,86 & 13,86 & $-5,50$ & $-3,29$ & $1022=$ \\
\hline 8,90 & 56718 & 434 & 66. & 13,62 & $-5,47$ & $-3,09$ & 2010. \\
\hline 9,0 & 57388 & 4410 & 66,99 & 13,77 & $-5,45$ & $-2,99$ & 3013,6 \\
\hline 9,20 & 52053 & -44778 & 67. & 13.72 & $-5,42$ & -2 . & 1016. \\
\hline 9,20 & 53727 & -45447 & 67,11 & 13,67 & $-5,39$ & $-2,79$ & $10: 22$ \\
\hline$-9,30$ & 59400 & 46120 & $-67,18$ & $\ldots 13,63$ & $-5,36$ & $-2,69$ & 1022,3 \\
\hline 9,40 & 60072 & 46 & 67,26 & $-13,59$ & -5.33 & -2.59 & 1025.5 \\
\hline 9,50 & 60745 & 47465 & 67 & 13,56 & $-5,30$ & $-2,48$ & $2023 \mathrm{i}$ \\
\hline 9,60 & 61418 & 48138 & 67,37 & 13,52 & $-5,27$ & $-2,33$ & 1031, \\
\hline$-9,70$ & -62092 & 48812 & 67,44 & $-13,49$ & $-5,23$ & $-2,22$ & 2034 \\
\hline 9,80 & 62767 & 49487 & 62,51 & $-13,45^{\circ}$ & $=5,20$ & $=2,17$ & 1032.3 \\
\hline 2,9 & .63443 & -50163 & 67 & 13. & $-5,12$ & -2 . & 2026 \\
\hline 10,0 & 6411 & & & 13,40 & -5.14 & -1.96 & $10 \div ;$ \\
\hline 10,10 & 64794 & & 67,72 & -13.37 & $-5,20$ & $-2,35$ & $20: 3$. \\
\hline 10,20 & 65473 & & 67,79 & 13,34 & -5.07 & $-1,75$ & 103 \\
\hline 10,30 & 66151 & 52871 & -67.86 & 13,32 & $-5,03$. & $-1,64$ & 203 \\
\hline 10. & 663 & -5.35 & 67,93 & 13 & $-5,00$ & $-1,53$ & 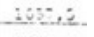 \\
\hline 10. & 675 & .542 & 63,00 & -13. & $-4,96$ & $-1,43$ & $1062=$ \\
\hline 10.60 & 63139. & 54229 & 68.07 & $-13,26$ & $-4,93$ & $-2,33$ & $: 063$. \\
\hline 10,70 & 68371 & 5559 & 68,14 & 13,24 & $-4,89$ & $-1,23$ & 1067. \\
\hline 10, & 6955 & .56 .273 & 63,20 & $-13,22$ & $-4,85$ & -1 , & $107 \mathrm{~s}$, \\
\hline
\end{tabular}

Figura 17: Capa do manual de estabilidade e tabela de dados hidrostáticos do navio classe "Panamax".

A figura 17 acima mostra a tabela de dados hidrostáticos do navio-tipo de classe idêntica ao apresentado. Dessa forma, multiplicando-se os valores médios da diferença de folga abaixo da quilha (transformados de metros para centímetros) pelo valor de 68,27 toneladas, obtém, para cada condição ambiental analisada no trabalho, os valores de toneladas a serem embarcadas, conforme tabela 9, mostrada a seguir:

Tabela 9: Cálculo da tonelagem a ser embarcada, para diferentes condições da análise.

\begin{tabular}{|c|c|c|c|c|c|c|c|c|}
\hline $\begin{array}{l}\text { Onda / } \\
\text { Veloc. Do } \\
\text { Vento }\end{array}$ & $\begin{array}{c}\text { Cond.1 } \\
\text { Alt:0,25m } \\
\text { Período: } \\
7 \mathrm{~s}\end{array}$ & $\begin{array}{c}\text { Cond.2 } \\
\text { Alt:0,35m } \\
\text { Período: } \\
8 \mathrm{~s}\end{array}$ & $\begin{array}{c}\text { Cond.3 } \\
\text { Alt:0,79m } \\
\text { Período: } \\
9 \mathrm{~s}\end{array}$ & $\begin{array}{c}\text { Cond.4 } \\
\text { Alt: } 0,47 \mathrm{~m} \\
\text { Período: } \\
10 \mathrm{~s}\end{array}$ & $\begin{array}{c}\text { Cond.5 } \\
\text { Alt:0,61m } \\
\text { Período: } \\
11 \mathrm{~s}\end{array}$ & $\begin{array}{c}\text { Cond.6 } \\
\text { Alt:0,85m } \\
\text { Período: } \\
12 \mathrm{~s}\end{array}$ & $\begin{array}{c}\text { Cond.7 } \\
\text { Alt:1,35m } \\
\text { Período: } \\
13 \mathrm{~s}\end{array}$ & $\begin{array}{c}\text { Cond.8 } \\
\text { Alt:1,55m } \\
\text { Período: } \\
14 \mathrm{~s}\end{array}$ \\
\hline$\frac{\frac{\text { VALORES }}{\text { MÉDIOS }}}{\frac{(\mathrm{m})}{}}$ & 0,360 & 0,586 & 0,544 & 0,339 & 0,268 & 0,261 & 0,190 & 0,049 \\
\hline$\frac{\text { VALORES }}{\frac{\text { MÉDIOS }}{(\mathrm{cm})}}$ & 36,00 & 58,60 & 54,40 & 33,90 & 26,80 & 26,10 & 19,00 & 4,90 \\
\hline $\begin{array}{c}\text { TPC do } \\
\text { navio-tipo } \\
\text { para } 10,90 \\
\text { metros de } \\
\text { calado }\end{array}$ & \multicolumn{8}{|c|}{68,27} \\
\hline $\begin{array}{l}\frac{\text { Quantidade }}{\text { de carga a }} \\
\frac{\text { ser }}{\text { embarcada }} \\
\text { (ton) }\end{array}$ & 2457,72 & 3997,21 & 3710,47 & 2310,94 & 1826,22 & 1781,85 & 1293,72 & 334,52 \\
\hline
\end{tabular}


Por consequência do cálculo, fica notável que os menores valores de carga a ser embarcada são aqueles de condições ambientais mais adversas (condições "7" e "8"), por terem apresentado as menores diferenças de valores de folga abaixo da quilha pela inclusão de 3 rebocadores nas manobras.

Em contrapartida, nas condições "2" e 3" do estudo, houve um incremento de 3997,21 e 3710,47 toneladas, respectivamente. Estes valores representam quase $5 \%$ do deslocamento de um navio desta classe a mais a ser transportada, por cada viagem.

\subsection{Obtenção dos valores médios de frete para carga a granel}

Em relação aos valores de frete (U $\$ D /$ ton) de carga embarcada em um naviotipo da classe "Panamax", é sabido que os preços são flutuantes e sua variação ocorre em função principalmente de 3 fatores:

- A rota a ser realizada pelo navio: viagens mais longas demandarão mais tempo de travessia e possuirão taxas de frete mais altas.

- A volatilidade de mercado: tal volatilidade é associada a fatores externos (preços da commodity negociados nas principais bolsas de valores do mundo, projeções de oferta e demanda, etc).

- O tipo de navio afretado: navios de diferentes classes (ex: Handymax, Panamax, Capesize, entre outros) e porte bruto possuirão taxas de frete diferente, para o mesmo período, e mesma rota.

Nos últimos anos, verificou-se uma marcante tendência de baixa nas taxas de afretamento, em todas as diferentes classes de navios de granel sólido, conforme mostrado na figura 18 abaixo, retirada de UNCTAD [18]. O mercado de granel sólido teve, em 2015, o máximo declínio desde 1999, no qual as receitas brutas dos navios classe "Capesize" tiveram os menores níveis, fortemente influenciados pela redução do crescimento da economia chinesa.

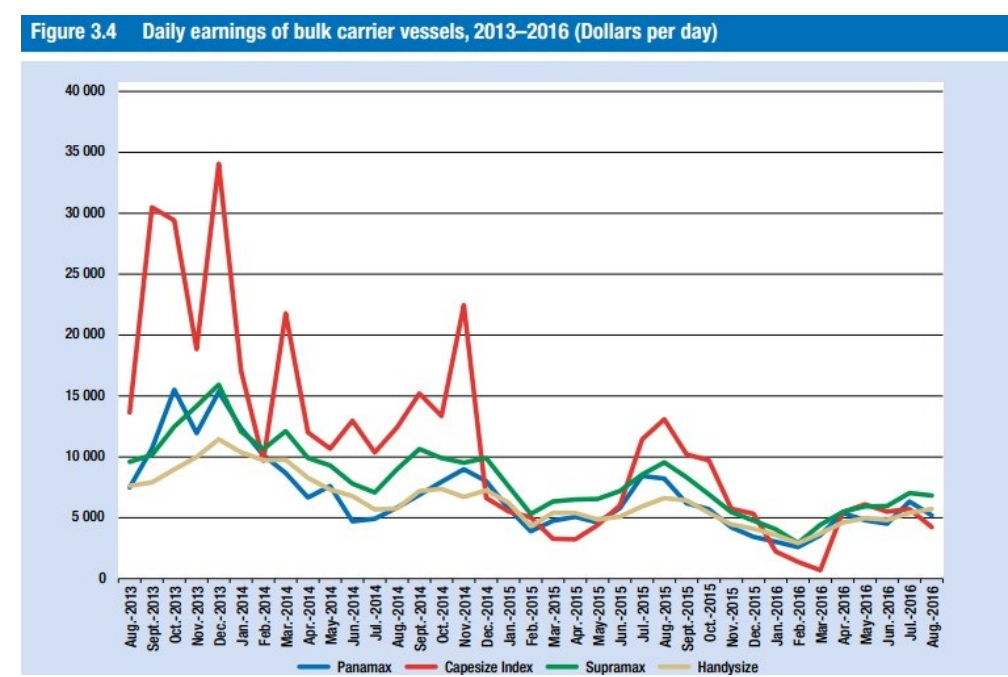

Figura 18: Queda nos valores de receita, entre os anos de 2013 e 2015, para os diferentes tipos de navios graneleiros. Fonte: UNCTAD [18].

Diante do exposto acima, para cálculo do frete a ser utilizado na análise, tomouse com base duas viagens internacionais do navio-tipo graneleiro da classe "Panamax", entre um porto brasileiro (Tubarão - ES) e 2 destinos internacionais de diferentes distâncias (Rotterdam - Holanda e Qingdao - China). Adicionalmente a 
este exemplo, em consulta com os dados de CLARKSON [19] e [20] e PLATTS [21], dados licenciados para uso da Universidade Federal do Rio de Janeiro, obteve-se as seguintes curvas de dados de frete, expostas na figura 19 abaixo:

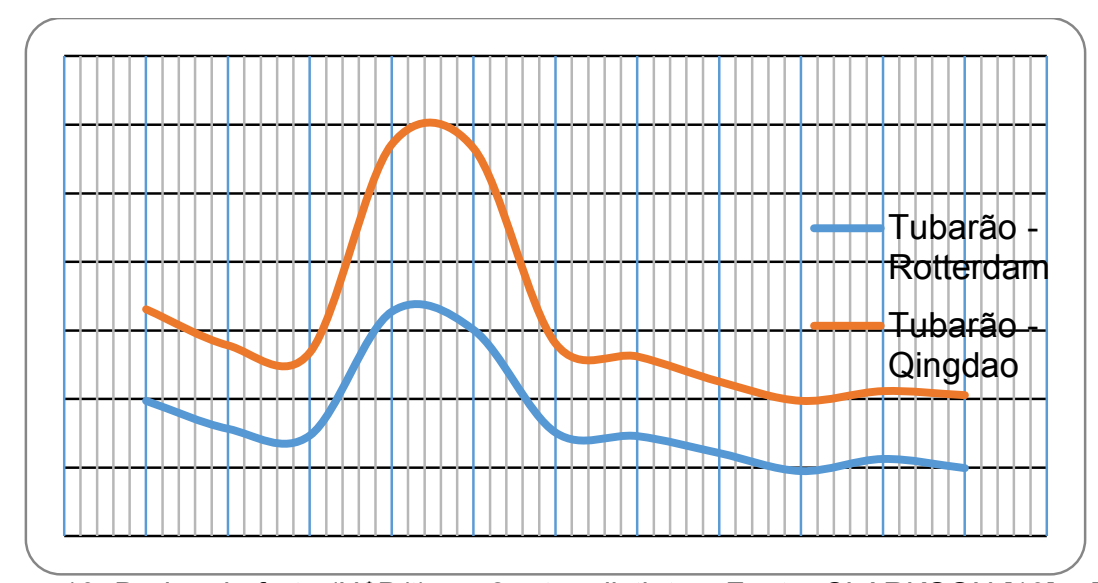

Figura 19: Dados de frete (U\$D/t) em 2 rotas distintas. Fonte: CLARKSON [19] e [20].

Nesta série história verifica-se a oscilação do valor do frete de granel no mercado internacional, entre os anos de 2004 e 2014. Entre as razões para tais oscilações, além das já citadas acima, de acordo com CLARKSON [20], o fato de o mercado naval mundial ter passado por um período de alta oferta de navios graneleiros, o que levou muitos armadores a terem receitas muito próximas dos custos de operação.

Para o objetivo de estimar o efeito quantitativo do ganho econômico devido ao aumento de calado, pode-se utilizar os valores extremos de frete: : um de maior valor na maior rota $(57,14 \mathrm{U} \$ \mathrm{D} / \mathrm{t}$ ton) e outro de menor valor na menor rota $(9,91 \mathrm{U} \$ \mathrm{D} /$ ton). Apresentam-se na tabela abaixo ambos os cenários para a quantidade de carga embarcada calculada.

Tabela 10: Cálculos de valores de aumento de receita bruta para 2 cenários de preços de frete e 2 cenários de rotas realizadas pelo navio-tipo.

\begin{tabular}{|c|c|c|c|c|c|c|c|c|}
\hline & Cond.1 & Cond.2 & Cond.3 & Cond.4 & Cond.5 & Cond.6 & Cond.7 & Cond. 8 \\
\hline $\begin{array}{l}\frac{\text { Quantidade }}{\text { de carga a }} \\
\frac{\text { ser }}{\text { embarcada }} \\
\text { (ton) }\end{array}$ & 2457,72 & 3997,21 & 3710,47 & 2310,94 & 1826,22 & 1781,85 & 1293,72 & 334,52 \\
\hline $\begin{array}{l}\frac{\text { CENÁRIO }}{\frac{1:}{\text { Menor }}} \\
\frac{\text { valor de }}{\text { Frete com }} \\
\frac{\text { a menor }}{\text { rota }(U \$ D /} \\
\text { Ton) }\end{array}$ & \multicolumn{8}{|c|}{9,91} \\
\hline $\begin{array}{l}\frac{\text { Aumento }}{\text { de receita }} \\
\frac{\text { para o }}{\text { armador }} \\
(U \$ D)\end{array}$ & 24356,01 & 39612.34 & 36770,80 & 22901,41 & 18097,86 & 17658,10 & 12820,73 & 3315,12 \\
\hline
\end{tabular}




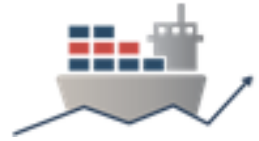

\begin{tabular}{|c|c|c|c|c|c|c|c|c|}
\hline$\frac{\text { (Pior }}{\text { cenário) }}$ & & & & & & & & \\
\hline $\begin{array}{l}\frac{\text { CENÁRIO }}{2:} \\
\frac{\text { Maior valor }}{\frac{\text { de Frete na }}{\text { maior rota }}} \\
\frac{\text { (U\$D } /}{\text { Ton })}\end{array}$ & \multicolumn{8}{|c|}{57,14} \\
\hline $\begin{array}{l}\frac{\text { Aumento }}{\text { de receita }} \\
\frac{\text { para o }}{\text { armador }} \\
\frac{(U \$ D)}{(\text { Melhor }} \\
\text { cenário) }\end{array}$ & 140434,12 & 228400,49 & 212016,51 & 132047,08 & 104350,05 & 101814,74 & 73922,96 & 19114,64 \\
\hline
\end{tabular}

\subsection{Obtenção do custo representativo pela utilização de 3 rebocadores} adicionais por manobra portuária

Para obtenção dos dados do custo representativo por manobra de um rebocador azimutal, foram realizadas algumas entrevistas com especialistas em rebocadores no Brasil, já que não há dados publicados pelas empresas de rebocadores e tampouco, pela Agência Nacional de Transportes Aquaviários (ANTAQ) que regula o setor.

Diante disso, estimou-se que o valor cobrado dos armadores seja algo em torno de U\$D 2750,00 por movimentação de rebocador azimutal, em média, nos portos brasileiros, levando-se em consideração uma idade média do rebocador inferior a 10 anos de uso, e levando-se em consideração um contrato de afretamento por tempo ("Time Charter Party"); neste modelo de contrato, o afretador do rebocador (por exemplo, um consórcio entre um proprietário do porto e um armador de um navio específico daquele porto) fica responsável apenas pela gestão comercial, deixando a gestão náutica (ex: custos com tripulação, combustíveis, alimentação, entre outros) a cargo da empresa de rebocadores.

Logo, com a inclusão de 3 rebocadores adicionais às manobras do navio classe "Panamax", o aumento representativo de custo pode ser considerado da ordem de U\$D 8250,00.

\subsection{Aumento de receita para o armador do navio}

Diante do exposto nos itens acima, chega-se a análise econômica final da operação. A avaliação envolve o trade-off entre o aumento de receita obtido pelo aumento do calado, de acordo com os valores de frete considerados, em detrimento do valor adicional de inclusão de rebocadores.

Seguindo a análise descrita nos itens anteriores, a tabela 11 abaixo apresenta esta análise final: 
VI CIDESPORT/2019

Congresso Internacional de Desempenho Portuário

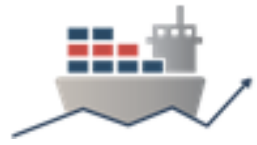

Tabela 11: Cálculo final de aumento ou redução de receita da operação, de acordo com a condição ambienta e os 2 cenários de preços de frete.

\begin{tabular}{|c|c|c|c|c|c|c|c|c|}
\hline & Cond.1 & Cond.2 & Cond.3 & Cond.4 & Cond.5 & Cond.6 & Cond.7 & Cond.8 \\
\hline$\frac{\frac{\text { Aumento de }}{\text { receita para }}}{\frac{\text { o armador }}{\text { (U\$D) }}}$ & 24356,01 & 39612.34 & 36770,80 & 22901,41 & 18097,86 & 17658,10 & 12820,73 & 3315,12 \\
\hline $\begin{array}{l}\frac{\begin{array}{l}\text { Aumento de } \\
\frac{\text { Despesas }}{\text { para o }}\end{array}}{\text { armador }} \\
\frac{\text { a inclusão de }}{\text { a inclevido }} \\
\frac{3}{\text { rebocadores }} \\
\text { adicionais }\end{array}$ & \multicolumn{8}{|c|}{8250,00} \\
\hline $\begin{array}{l}\frac{\overline{\text { Diferença }}}{\text { (Receita - }} \\
\frac{\text { Despesa) }}{\text { para o }} \\
\frac{\text { Armador }}{\text { (Pior }} \\
\frac{\text { Cenário) }}{(U \$ D)}\end{array}$ & 16106,01 & 31362,34 & 28520,80 & 14651,41 & 9847,86 & 9408,10 & 4570,73 & $49 \overline{4}, 88$ \\
\hline 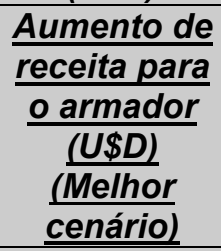 & 140434,12 & 228400,49 & 212016,51 & 132047,08 & 104350,05 & 101814,74 & 73922,96 & 19114,64 \\
\hline $\begin{array}{l}\frac{\text { Aumento de }}{\text { Despesas }} \\
\text { para o } \\
\frac{\text { armador }}{(U \$ \mathrm{DD}) \text {,devido }} \\
\frac{\text { a inclusão de }}{3} \\
\frac{\underline{3}}{\text { rebocadores }} \\
\text { adicionais }\end{array}$ & & & & 8250 & & & & \\
\hline $\begin{array}{l}\frac{\overline{\text { Diferenca }}}{\text { (Receita }} \\
\frac{\text { Despesa) }}{\text { para o }} \\
\frac{\text { Armador }}{\text { (Melhor }} \\
\frac{\text { Cenário) }}{(U \$ D)}\end{array}$ & 132184,12 & 220150,49 & 203766,51 & 123797,08 & 96100,35 & 93564,74 & 65672,96 & 10864,64 \\
\hline
\end{tabular}

Após análise da tabela 11, verifica-se que em grande parte das condições ambientais apresentadas, a operação final geraria aumento de receita; em algumas, o aumento de receita é mínimo e pode não ser compensatório; e em uma condição analisada, houve redução da receita.

Diante deste cenário, são geradas as seguintes conclusões:

1. Levando-se em consideração a rota mais curta para o navio graneleiro e o pior cenário no valor do frete de granel - ano de 2014 - segundo os 
relatórios CLARKSON [19] e CLARKSON [20], utilizados como base para as análises:

Existiu uma condição ambiental - condição "8" - que houve redução de receita para o armador, respectivamente no valor de U\$D 4.934,88. Isto se deu, pois esta foi a condição que houve a menor diferença nos valores de folga abaixo da quilha pela inclusão de 3 rebocadores na manobra.

Existiram outras três condições ambientais - condições "5", "6" e "7", que houve um baixo valor de aumento de receita, inferior a U\$D $10.000,00$, sendo assim uma margem de lucro muito pequena para uma operação deste tipo.

Considera-se que tais operações poderiam trazer redução de receita para o armador, caso o valor do afretamento do rebocador por manobra fosse um pouco superior ao valor considerado, ou o modelo de contrato de afretamento do rebocador fosse outro que envolvesse maiores custos ao armador do navio. Isto poderia ocorrer, por exemplo, em um modelo de contrato de afretamento a casco nu, em que o afretador do rebocador (no exemplo, o armador) ficasse responsável, além da gestão comercial, também pela gestão náutica do rebocador afretado; ocorreria uma elevação dos custos com tripulação, combustível, manutenção, que, sendo geridos pelo armador do navio, poderia tornar a operação não economicamente rentável.

Existiram outras 2 condições - "1" e " 4 " - que geraram um aumento de receita pouco maior que U\$D 10000,00, e que podem ser usadas como parâmetros para uma época que os valores de frete estiverem tão baixos.

Por fim, nas condições "2" e "3", houve um aumento de receita considerável, gerando uma margem de aumento de receita bem maior que as outras condições.

2. Levando-se em consideração a rota mais longa e o maior valor do frete a granel, que, na estatística apresentada nos relatórios CLARKSON [19] e CLARKSON [20], foi no ano de 2007, podemos concluir o seguinte:

Nenhuma das condições apresentou redução de receita;

Apenas em uma das condições - condição "8" - apresentou um pequeno aumento de receita. Consoante já exposto anteriormente no item 4.1, a condição " 8 " foi aquela que apresentou os menores valores de diferença entre os dados encontrados de folga abaixo da quilha, tendo como consequência disso, apresentado um aumento de receita total de aproximadamente U\$D 10.864,64. Este valor pode ser considerado pequeno para a operação, e pode ser que, em outro modelo de contrato de afretamento do rebocador ou, sob outro valor de afretamento, a operação leve a redução de receita;

Em todas as outras 7 condições houve significativo aumento de receita para o armador, com destaque para as condições " 2 " e "3", que foram 
aquelas que o estudo resultou em maiores valores de diferença de folga abaixo da quilha, e cujos valores de aumento de receita ultrapassaram os U\$D $200.000,00$.

A partir destas conclusões, pode-se gerar dois gráficos com os valores de receita, de acordo com os dois cenários de frete e as condições ambientais analisadas, conforme figura mostrada a seguir.

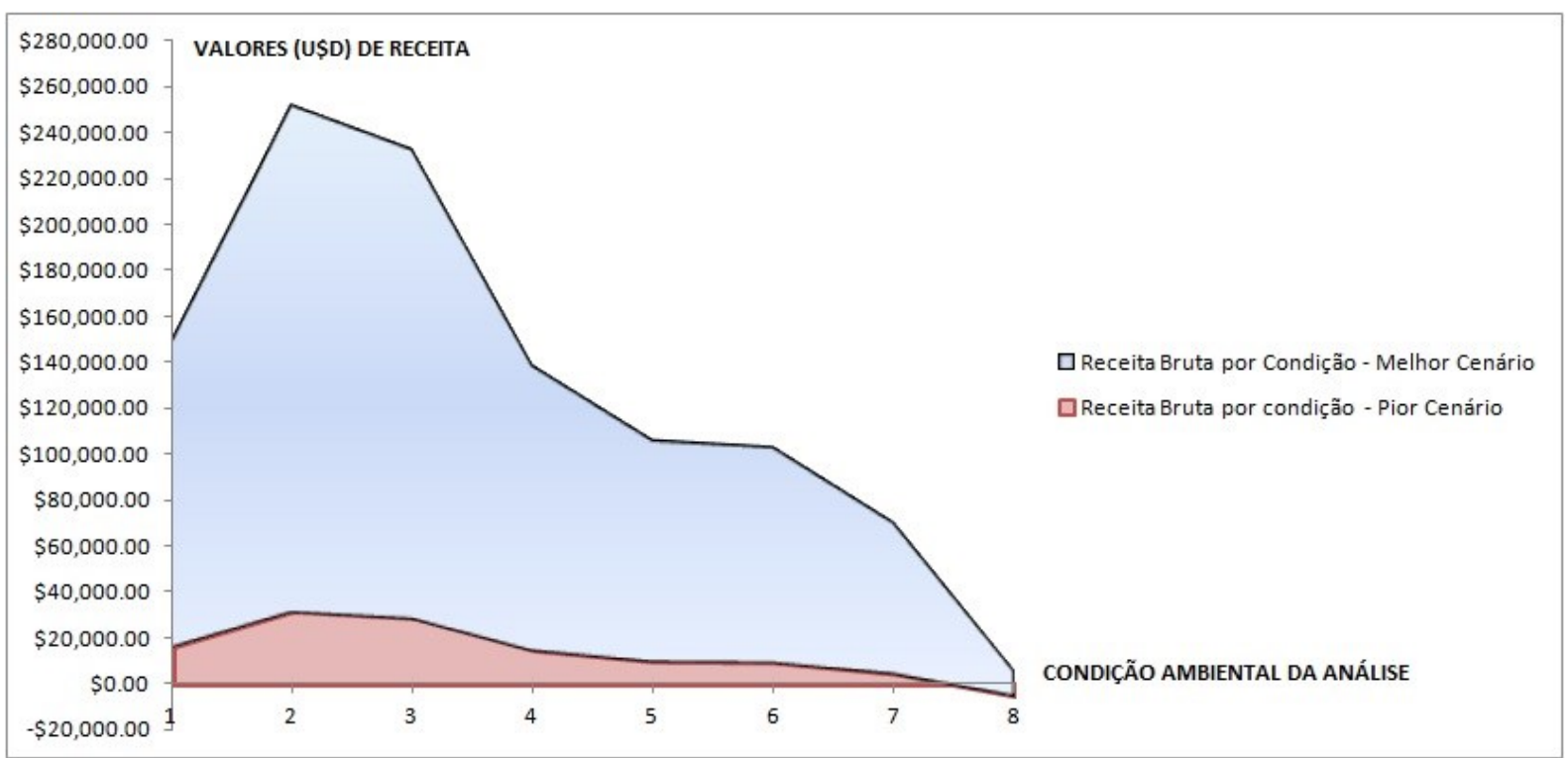

Figura 20: Apresentação dos 2 cenários de receita de acordo com o valor do frete e condição ambiental da análise.

\section{CONCLUSÕES E CONTRIBUIÇÃO ESPERADA}

O advento de novas construções de navios mercantes gerou um aumento nas suas principais dimensões: comprimento, boca (estas dimensões horizontais) e calado (dimensão vertical). Mormente o calado de projeto dos navios tenha aumentado em grande extensão nos últimos projetos de navios construídos nos estaleiros mundiais e ainda, que este aumento ocorreu de maneira independente da classe e tipo de carga que o navio transporta, os portos brasileiros permaneceram com as mesmas dimensões.

O estudo apresentado neste artigo apresentou uma análise metodológica alternativa de uso de rebocadores para auxílio nas manobras de navios, com fito de retirar um dos maiores gargalos portuários encontrados na grande maioria dos portos nacionais: os valores mínimos de folga abaixo da quilha que os navios devem respeitar nas manobras pelos canais de acesso, reduzindo as probabilidades de encalhe.

Em acréscimo às conclusões já apresentadas no capítulo anterior, algumas ressalvas quanto a estas conclusões são importantes para as contribuições deste trabalho:

1. A metodologia utilizada é uma ferramenta útil e relevante para aumento de carga transportada e de receita, e deve ser conjugada com as situações específicas e condições ambientais do caso concreto do canal de acesso analisado. A consideração de que o canal de acesso deve ter a mesma profundidade em toda a sua extensão tem alta relevância para a consistência dos resultados finais. 
2. A ordem de grandeza do aumento de calado, e por consequência, de aumento de carga a ser transportada varia principalmente com a condição ambiental analisada e com a capacidade dos rebocadores em gerarem forças de frenagem suficientes para reduzir a velocidade do navio-tipo;

3. Os resultados e a ordem de grandeza do aumento de receita obtida indicam um limite para este aumento. Este limite depende do valor do frete e da condição ambiental que o navio realizou a manobra.

4. Análises mais detalhadas e obtenção de conclusões mais significativas sobre a ordem de grandeza do aumento de carga a ser transportada devem ser feitas para o caso específico. Os seguintes detalhes possuem relevância para os resultados: o conhecimento específico das condições ambientais do porto, da modelagem do comportamento do afundamento do navio-tipo no simulador de manobras utilizado, bem como das possíveis forças de frenagem e governo geradas pelos rebocadores, durante assistência do navio-tipo nas manobras.

\section{REFERÊNCIAS}

[1] HENSEN, Henk. Tug Use in Port - A Practical Guide. Nautical Institute. $2^{\text {nd }}$. Edition. 2002.

[2] ABNT NBR 13246/95: Planejamento Portuário

[3] PIANC - Permanent International Association of Navigation Congress - Report 121 - 2014: Harbour Approach Channels and Design Guidelines. 2014.

[4] TEJADA F. \& COHEN, I. (2009). Escort Towing in the Expanded Panama Canal. International Conference on Maritime Simulation. Panama. 2019.

[5] CASACA, Ana C. Paixão \& CASACA, Manuel (2017): The impact of muddy bottoms in ports, Maritime Policy \& Management, DOI: 10.1080/03088839.2017.1309471.http://dx.doi.org/10.1080/03088839.2017.1309471. $>$

[6] BARRASS, C.B; DAND, Ian W. Squat Interaction Manoeuvring, Nautical Institute, 1995.

[7] GRONARZ, A. Development of a Squat Formula based on numerical calculations (2016). $4^{\text {th }}$ MASHCON (International Conference on Ship Manoeuvring in Shallow and Confined Water). Hamburg, Germany.2016.

[8] McCARTNEY, Bruce, L., et al. SHIP CHANNEL AND DESIGN OPERATION. ASCE Manuals and Reports on engineering practice. No.107. ASCE - American Society of Civil Engineers. 2005.

[9] ROM 3.1 -99: RECOMMENDATIONS FOR MARITIME WORKS. Design of the Maritime Configuration of Ports, Approach Channels and Harbour Basins. Gobierno de España. 2000.

[10] GOURLAY, T.P. "Ship Underkeel Clearance in Waves". Proc. Coasts and Ports, Melbourne, July 2007. pp. 1-6.Disponível em < http://cmst.curtin.edu.au/wp- 
VI CIDESPORT/2019

Congresso Internacional

de Desempenho Portuário

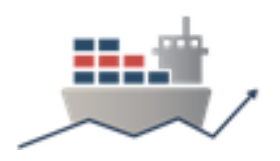

content/uploads/sites/4/2016/05/gourlay-2007-

ship underkeel clearance in waves.pdf>. Acesso em 20.02.2017.

[11] PARKER, Bruce B; HUFF, Lloyd C. "Modern Underkeel Clearance Management". International Hydrographic Review. Monaco. September 1998.Disponívelem<https://journals.lib.unb.ca/index.php/ihr/article/view/22959/26656 >. Acesso em 22.02.2017.

[12] LEWIS, Edward V. PRINCIPLES OF NAVAL ARCHITECTURE. Vol. III Motions in Waves and Controllability. Society of Naval Architects and Marine Engineers. 1989.

[13] MARINHA DO BRASIL, CPRJ, 2012. Normas e Procedimentos da Capitania dos Portos do Rio de Janeiro. Disponível em https://www.mar.mil.br/cpri/npcp.html>. Acesso em 01.02.2017

[14] PETROBRÁS. METEOCEAN DATA. PROJECT: LNG Terminal of Guanabara Bay-RJ. No. I-ET-4155.52-6611-941-PPC-001.rev.A. 26.04.2012.

[15] LOBO, Paulo R. Valgas, e SOARES, C. Alberto. METEOROLOGIA E OCEANOGRAFIA. Usuário Navegante. Diretoria de Hidrografia e Navegação. DHN. Rio de Janeiro. 2a . Edição. 2010.

[16] LARSSON, L \& RAVEN, Hoyte C. THE PRINCIPLES OF NAVAL ARCHITECTURE. Ship Resistance and Flow. Society of Naval Architects and Marine Engineers. 2010.

[17] VEROLME ESTALEIROS REUNIDOS DO BRASIL S.A. Manual de Trim e Estabilidade (incluindo cálculo dos esforços longitudinais) - final. Navio Graneleiro de 70.000 TPB. Casco 54 - DOCEALFA.

[18] UNCTAD - United Nations Conference on Trade and Development. Review of Maritime $\quad$ Transport. 2016.2 Disponível em http://unctad.org/en/PublicationsLibrary/rmt2016 en.pdf>. Acesso em 20.04.2017.

[19] CLARKSON Research Services. "Dry Bulk Trade Outlook". Volume 16. No. 6. ISSN : 1361 - 3189. pp. 1 -24. June 2010.

[20] CLARKSON Research Services. "Dry Bulk Trade Outlook". Volume 21. No. 3. ISSN 1361 - 3189. pp. 1-24. March - 2015.

[21] PLATTS SHIPPING, S\&P Global. "Dry Freight Wire”, Vol. 4. Issue 1. January 3, 2017. 